\title{
Dual technology energy storage system applied to two complementary electricity markets using a weekly differentiated approach
}

\author{
Helder Lopes Ferreira ${ }^{\mathrm{a}, *}$, Kateřina Staňkováb,c ${ }^{\mathrm{b}}$, João Peças Lopes ${ }^{\mathrm{d}, \mathrm{e}}$, \\ Johannes Gerlof (Han) Slootwega , Wil L. Kling ${ }^{\mathrm{a}, 1}$ \\ a Department of Electrical Engineering, Eindhoven University of Technology, Den Dolech 2, Eindhoven, The Netherlands \\ ${ }^{\mathrm{b}}$ Department of Knowledge Engineering, Maastricht University, Bouillonstraat 8-10, Maastricht, The Netherlands

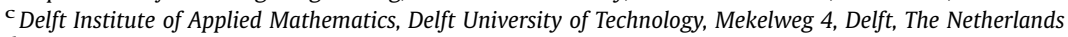 \\ d Electrical Engineering Department, University of Porto, Rua Dr. Roberto Frias 378, Porto, Portugal \\ e INESCTEC - Technology and Science \& FEUP, Institute for Systems and Computer Engineering of Porto, Rua Dr. Roberto Frias 465, Porto, Portugal
}

\section{A R T I C L E I N F O}

\section{Article history:}

Received 6 June 2016

Received in revised form 19 March 2017

Accepted 17 April 2017

Available online $\mathrm{xxx}$

\section{Keywords:}

Energy storage systems

Electricity markets

Renewable energy sources integration

Optimal control

Optimization

\begin{abstract}
A B S T R A C T
This paper deals with integration of energy storage systems into electricity markets. We explain why the energy storage systems increase flexibility of both power systems and energy markets and why such flexibility is desirable, particularly when variable renewable energy sources are being used in existing power systems. As opposed to the existing literature, our model includes a dual technology energy storage system, acting in two different markets. We introduce a mathematical formulation for this model applied to two Dutch electricity markets. Adopting optimal control approach with the goal to maximize the yearly benefit, we show that the dual energy storage system can be profitable already when the same buying/selling strategies are adopted for the working days and weekends. We show that the profitability (slightly) increases with different buying/selling strategies for the weekdays and weekends. Finally, we demonstrate how the yearly benefit varies with size and efficiency of the devices chosen and market prices.
\end{abstract}

(C) 2017 Published by Elsevier Ltd.

\section{Introduction}

\subsection{Motivation, background and literature review}

The worldwide energy policy goals include further integration of the renewable generation technologies into the energy markets. For example, the European Union is striving to achieve $20 \%$ of energy generated from renewable energy sources (RES) by 2020 and to reach a minimum of $27 \%$ of renewable generated energy by 2030 , while reducing greenhouse gas emissions by at least $40 \%$ by 2030 compared to their level in 1990 [1]. Objectives for 2050 are even more challenging, with a reduction of the carbon emissions by $80-95 \%$ [2]. All around the world (e.g. in China [3], Japan [4], New Zealand [5], United States of America [6,7] and Turkey [8]) the power systems are being prepared for an increasing level of deployment of renewable generation technologies.

\footnotetext{
* Corresponding author.

E-mail address: h.m.lopes.ferreira@gmail.com (H.L. Ferreira).

1 Deceased.
}

In conjunction with RES, the integration of other recent technologies, such as electric vehicles (EV), but also the unbundling and modification in the regulation of the power sector, influence the paradigm and structure of the power sector. As electricity has to be dealt with when generated, either by being consumed or stored, matching the levels of generation and load at all times is fundamental. The fact that most RES are weatherdependent will cause the generation output to vary more likely with the climate conditions than with the market needs. The increasing integration of electric vehicles also increases the likelihood of high load variations during the day. The novel technologies are expected to be applied to an extent which will certainly amplify the effect of these variations.

The above mentioned technological and regulatory developments call for adjustment of planning and operation of the power systems - they need to be more flexible. This flexibility can be achieved through several technologies and techniques (e.g. energy storage systems (ESSs'), cross-border interconnection capacity, RES management, more flexibility from conventional generation, active demand side management and vehicle-to-grid) and their combinations [9]. Among these, ESS is seen as one of the long term most feasible options to achieve that goal [10]. 
ESSs can provide up to twice their rating (sum of charge and discharge capacities) to balance the electricity grid. This is accomplished by switching between the two modes of charging and discharging, in either direction (from charging to discharging or from discharging to charging). Therefore, ESSs help to balance the electricity system when there is a generation surplus or a deficit. ESSs can provide various services, most important of which belong to one of the two major categories:

- power market arbitrage

- ancillary services and balancing

Power market arbitrage is an energy service provided via charging an energy storage device when the electricity prices are low and discharging it when the prices are high [11]. The price variations are caused by daily, weekly or seasonal cycles. Lately, also variations in renewable power generation, e.g. wind and solar energy, are affecting the energy markets to a degree depending on their level of market penetration and the flexibility of the underlying conventional generation fleet. The most adequate markets exercising arbitrage are day-ahead and intra-day markets [12].

In unbundled markets, the system operators are not allowed to own energy generation assets. Therefore, they need to procure several ancillary services. Examples of these ancillary services are balancing support and congestion management.

Other services can be supplied by ESSs $[6,7,11]$, depending on the characteristics of the specific energy storage technologies. The problem of energy storage integration into existing electricity markets was studied in [13-15]. The literature implies that in most markets, with current price differences, arbitrage provision is not sufficient to make energy storage profitable. Hybrid energy storage systems using two energy storage devices are present in the literature. However, these are associated with electric vehicle power system or variable renewable energy generation site integration into the grid [16]. Nonetheless, to the best of our knowledge, no models including two electricity markets and two ESS technologies operating in parallel have been developed so far.

This paper focuses on a combination of energy market arbitrage and provision of balancing support by the same dual energy storage system. The model that we introduce in this paper differs from the models analysed in the literature in two major aspects. Firstly, we consider a system combining arbitrage and ancillary services. With this combination we expect higher yearly benefits than using arbitrage only. Secondly, the energy storage system that we propose uses two energy storage technologies simultaneously. The dual technology system was chosen in order to profit from characteristics of both devices and market price variations. This paper extends our research presented in [17].

In order to see how profitable the ESS could be, in this paper we seek optimal strategy in terms of price thresholds for buying and selling electricity at the Dutch day-ahead and balancing electricity markets. Mathematically, we formulate the problem as an optimal control problem with the goal to maximize the yearly benefit. Firstly, we consider the situation when buying and selling thresholds may vary between working days and weekends. Secondly, we consider a situation when the working days and weekend thresholds are the same. We use pattern search to find the optimal strategy and motivate the choice of this method.

The remainder of this paper is composed as follows. Section 2 introduces electricity markets in The Netherlands. Section 3 explains the background of the model we put forward. The problem dealt within this paper is defined mathematically in Section 4. Implementation of the model and a solution method are described in Section 5. Section 6 presents and discusses the results of the case studies. Section 7 finalizes the paper with the conclusions and directions for future research.

\subsection{Notation}

Tables 1 and 2 describe the main symbols used in this paper.

\section{Electricity markets in The Netherlands}

In The Netherlands most of the electricity is still traded in the bilateral market, where the generation companies sell the electricity directly to large consumers, traders and supply companies. The remaining electricity generated is traded in one of the two spot markets: the day-ahead and intra-day markets. For balancing purposes also a dedicated market exists, managed by the Dutch transmission system operator (TSO) TenneT. The day-ahead and intra-day markets have distinct dimensions. For 2011, about $40 \mathrm{TWh}$ of electricity were traded in the day-ahead market and less than $1 \%$ of that value, $278 \mathrm{GWh}$, were traded in the intra-day market [19]. The Netherlands has been identified as "the most promising [electricity market] for mass storage" [18].

\subsection{Day-ahead market}

The Dutch day-ahead market is active every day prior to the day of operation and closes at noon. This market has an hourly time unit. Unless stated differently, in this paper we use price data from 2014. For this year, we calculated the mean price of energy per MWh for the Dutch day-ahead market: $41.18 € /$ MWh. Fig. 1 depicts the average prices for 2014 and both day-ahead and balancing market. It is possible to observe the weekend variation in the dayahead market in the last two days, where prices tend to be lower than during the weekdays.

\subsection{Balancing market}

Balancing markets are volatile, and are used to balance the unattended mismatch between generation and load. In The Netherlands, the balancing market, also called imbalance market, works with a time unit of $15 \mathrm{~min}$. This unit is also called program time unit (PTU). This market is managed by TenneT, the national transmission system operator (TSO). The TSO tries to avoid the mismatch mentioned as much as possible by sharing balancing responsibilities with balancing responsible parties (BRPs). Each BRP aggregates a part of the consumers and generators in the network. The BRPs submit their daily zero-sum consumption and generation plans ex-ante. Each of these plans include their expected net energy exchange with the other BRPs to the TSO. Afterwards, in real time, the TSO verifies if there is any imbalance in the system.

There are two types of BRPs, those specifically asked to provide balancing capacity by active contributions (Balancing Service Providers - BSPs) and those either using the imbalance settlement system for their own imbalance or being active without being selected [20]. By bidding on the imbalance market, each BRP gives the TSO the right (but not the obligation) to buy balancing energy.

Load forecasting is not exact and energy generation forecasting with increasing integration of variable renewable-based generation is harder to achieve. Thus, the balancing market is used to solve these unexpected variations, by trading flexibility. Traditionally, this was achieved by increasing or decreasing generation [21]. Recently, whenever available, also demand side response and energy storage may be used [21], as long as the technologies used can cope with the response time required by the system operator.

The Dutch imbalance market has 4 possible modes: downwards, upwards, upwards/downwards and no contribution, which 
Table 1

Main symbols used in this paper, their meaning, and units (if applicable).

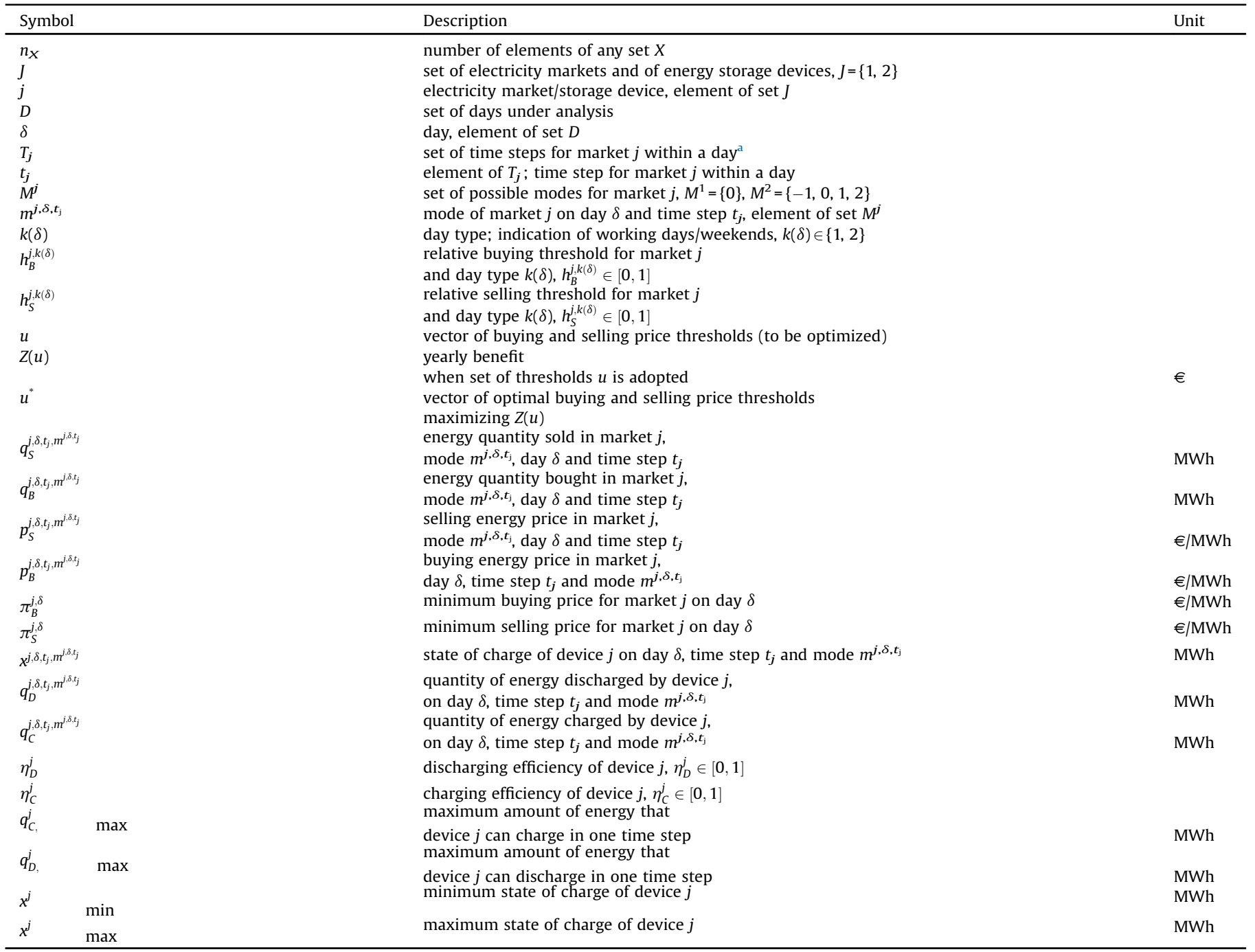

a Typical values: 24 time units for an hourly market, 96 time units for market with quarters of hour as a basic time unit.

we will denote by $-1,1,2$ and 0 , respectively (see Table 3 ). These modes are calculated by the TSO in the real time. In mode -1 there is an excess of power in the system. This excess of power is also called "long" and requires downward regulation. In mode 1 there is a lack of power in the system. This lack of power is also called "short" and requires upward regulation. In mode 2 there are periods of both excess and lack of power in the system within the time step of $15 \mathrm{~min}$, while in mode 0 there is no imbalance.

Based on data from 2014, we calculated the average price of energy per MWh for the Dutch balancing market: for upward regulation (mode 1 ) it is $38.31 € / \mathrm{MWh}$ and for downward regulation (mode -1 ) it is $11.12 € / \mathrm{MWh}$. The prices in this market vary during the week as shown in Fig. 1. Fig. 2 shows the frequency of 2014 prices for both day-ahead and balancing markets (upward and downward). The two figures suggest that the prices vary more in the balancing market than in the day-ahead market.

As the yearly benefit of the dual energy storage system depends on the price fluctuations in both markets, we have calculated the historical price volatility of the prices, which is a measure of price fluctuations observed over a given time period (e.g. hourly, daily, weekly or yearly) [21,22], see also Appendix A for details of its calculation. Fig. 3 shows the 2014 price volatility towards the previous time slot of the same day (one hour in the day ahead market and one PTU in the balancing market) for the three types of prices of the two markets. Clearly, the balancing market is more volatile than the day-ahead market

\section{Model Background}

In this section we introduce the background of our model. The two energy storage technologies considered are a high energy (bulk) and a high power technology, trading in the day-ahead and balancing markets, respectively.

The model is built from the point of view of the owner of the energy storage system, with the goal of maximizing the yearly benefit. The day-ahead market is used to perform energy price arbitrage and the balancing market is used to provide ancillary service support.

Fig. 4 depicts the relationship between the considered markets and the two types of energy storage devices. We have built two partial models, each of them describing the behaviour of one of these devices (see Section 5 for details). 

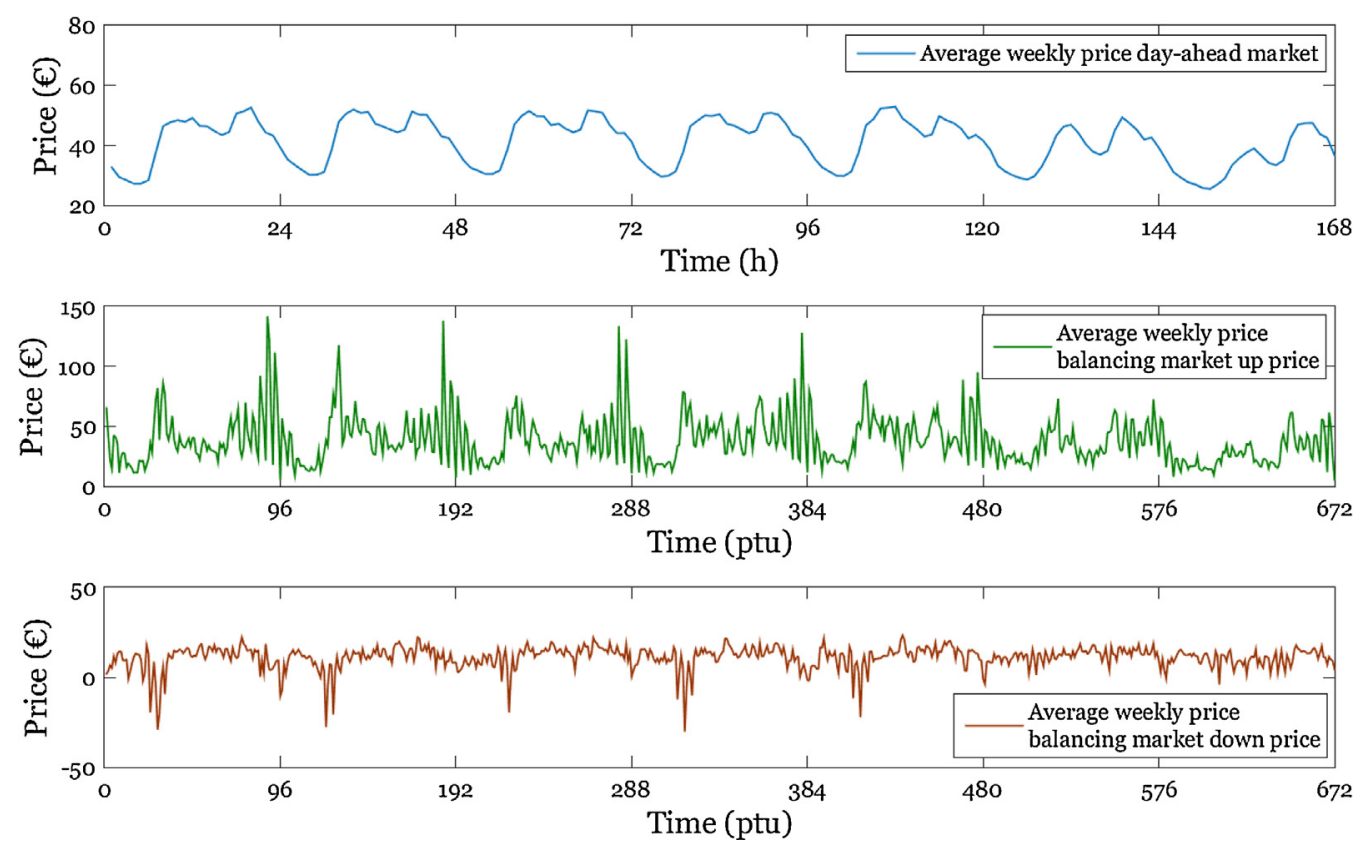

Fig. 1. Average weekly prices for both day-ahead and balancing markets 2014 .

Table 2

Main symbols used in this paper, their meaning, and units (if applicable), continuation of Table 1.

\begin{tabular}{|c|c|c|}
\hline Symbol & Description & Unit \\
\hline$\lambda^{2, \delta, t_{2}, m^{2, \delta, t_{2}}}$ & $\begin{array}{l}\text { energy received by device } 2 \text {, transferred from } \\
\text { device } 1 \text {, on day } \delta \text {, time step } t_{2} \text { and mode } m^{2, \delta, t_{2}}\end{array}$ & MWh \\
\hline$\gamma^{1, \delta, t_{1}, m^{1, \delta, t_{1}}}$ & $\begin{array}{l}\text { energy reserved by device } 1 \text { to be transferred } \\
\text { to device } 2 \text { on day } \delta \text {, time step } t_{1} \text { and mode } m^{1, \delta, t_{1}}\end{array}$ & MWh \\
\hline$\phi^{1, \delta, t_{1}, m^{1, \delta, t_{1}}}$ & $\begin{array}{l}\text { energy reserved on device } 1 \text { and not used to } \\
\text { supply device } 2 \text { on day } \delta \text {, time step } t_{1} \text { and mode } m^{1, \delta, t_{1}} \\
\text { historical price volatility in market } j \text { for day } \delta\end{array}$ & MWh \\
\hline${ }_{t_{j}-t_{j-1}}$ & $\begin{array}{l}\text { and time difference } t_{j}-t_{j-1} \\
\text { price return, }\end{array}$ & \\
\hline$v_{t_{j}-t_{j-1}}$ & $\begin{array}{l}\text { ratio between prices at time step } t_{j} \text { and } \\
\text { at time step } t_{j-1} \text {, for market } j \text { and day } \delta\end{array}$ & \\
\hline $\bar{v}^{j, \delta}$ & mean price return in market $j$, day $\delta$ & \\
\hline$\psi^{j}$ & $\begin{array}{l}\text { minimum payback period } \\
\text { for the technology } j \text { under analysis }\end{array}$ & years \\
\hline$\rho^{j}$ & power rating of device $j$ & $\mathrm{~kW}$ \\
\hline$\mu^{j}$ & cost per unit of power of device $j$ & $€ / \mathrm{kW}$ \\
\hline$\varepsilon^{j}$ & energy rating of device $j$ & $\mathrm{~kW}$ \\
\hline$\xi^{j}$ & cost per unit of energy of device $j$ & $€ / \mathrm{kWh}$ \\
\hline$o^{j}$ & $\begin{array}{l}\text { yearly fixed operation } \\
\text { and maintenance costs for device } j\end{array}$ & $€$ \\
\hline$\kappa^{j}$ & $\begin{array}{l}\text { variable operation and maintenance } \\
\text { costs for device } j\end{array}$ & $€ / \mathrm{kWh}$ \\
\hline$\iota$ & internal rate of return & $\%$ \\
\hline Y & total number of years & years \\
\hline$y$ & element of $Y$ & years \\
\hline
\end{tabular}

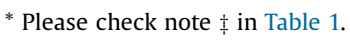

For the sake of simplicity, in our model we assume both perfect electricity price forecast and a price taker approach, based on two assumptions:

- The storage size is not big enough to modify market prices [23].

- There is a perfect forecast window, more or less extended according to the study [23].

These two assumptions are very standard when analysing potential profitability of energy storage systems in a modelling framework.
Table 3

Balancing modes in The Netherlands, based on [20].

\begin{tabular}{lllll}
\hline Balancing mode $\left(m^{2, \delta, t_{2}}\right)$ & -1 & 0 & 1 & 2 \\
\hline Condition & Long & $\begin{array}{l}\text { No } \\
\text { (Downward) }\end{array}$ & $\begin{array}{l}\text { Short } \\
\text { Imbalance }\end{array}$ & $\begin{array}{l}\text { Both long } \\
\text { (Upward) }\end{array}$ \\
\hline
\end{tabular}

\section{Model formulation}

Our goal is to find the optimal charge and discharge relative price boundaries, per device type and day, so that the yearly benefit obtained is maximized. Mathematically speaking, the problem of finding the optimal strategy for the energy storage system operation, composed of the finite set $J$ of storage devices, can be formulated as an optimal control problem. For the sake of simplicity, we assume that each device has a unique type and that this type uniquely identifies the type of market it is used for. ${ }^{2}$ This paper considers $J=\{1,2\}$, where $j=1$ identifies both Dutch dayahead electricity market and bulk energy storage device, while $j=2$ identifies both Dutch balancing electricity market and high power energy storage device. For clarification on the meaning of the main variables used in our model, please see Tables 1 and 2 .

Mathematical formulation of the optimal control problem dealt with in this paper reads as follows:

$u^{*}=\arg \quad \max _{u \in U} Z(u)$,

where the yearly benefit $Z(u)$ for the vector of relative price thresholds $u=\left(h_{B}^{1,1}, h_{S}^{1,1}, \ldots, h_{B}^{2,2}, h_{S}^{2,2}\right)$ is defined as

$\sum_{j \in J} \sum_{\delta \in D} \sum_{t_{j} \in T_{j}} \sum_{m^{j, \delta, t_{j}} \in M^{j}}\left(q_{S}^{j, \delta, t_{j}, m^{j, \delta, t_{j}}} \cdot p_{S}^{j, \delta, t_{j}, m^{j, \delta, t_{j}}}-q_{B}^{j, \delta, t_{j}, m^{j, \delta, t_{j}}} \cdot p_{B}^{j, \delta, t_{j}, m^{j, \delta, t_{j}}}\right)$,

with respect to Eqs. (3)-(26). Here $U=([0,1])^{2 \cdot n_{\mathrm{K}} \cdot n_{\mathrm{J}}}$ and $h_{B}^{j, k(\delta)}$ and $h_{S}^{j, k(\delta)}$ belong to the set $[0,1]$ and are relative buying and selling

\footnotetext{
${ }^{2}$ However, this assumption does not change the main ideas behind the model
} and can be easily relaxed. 

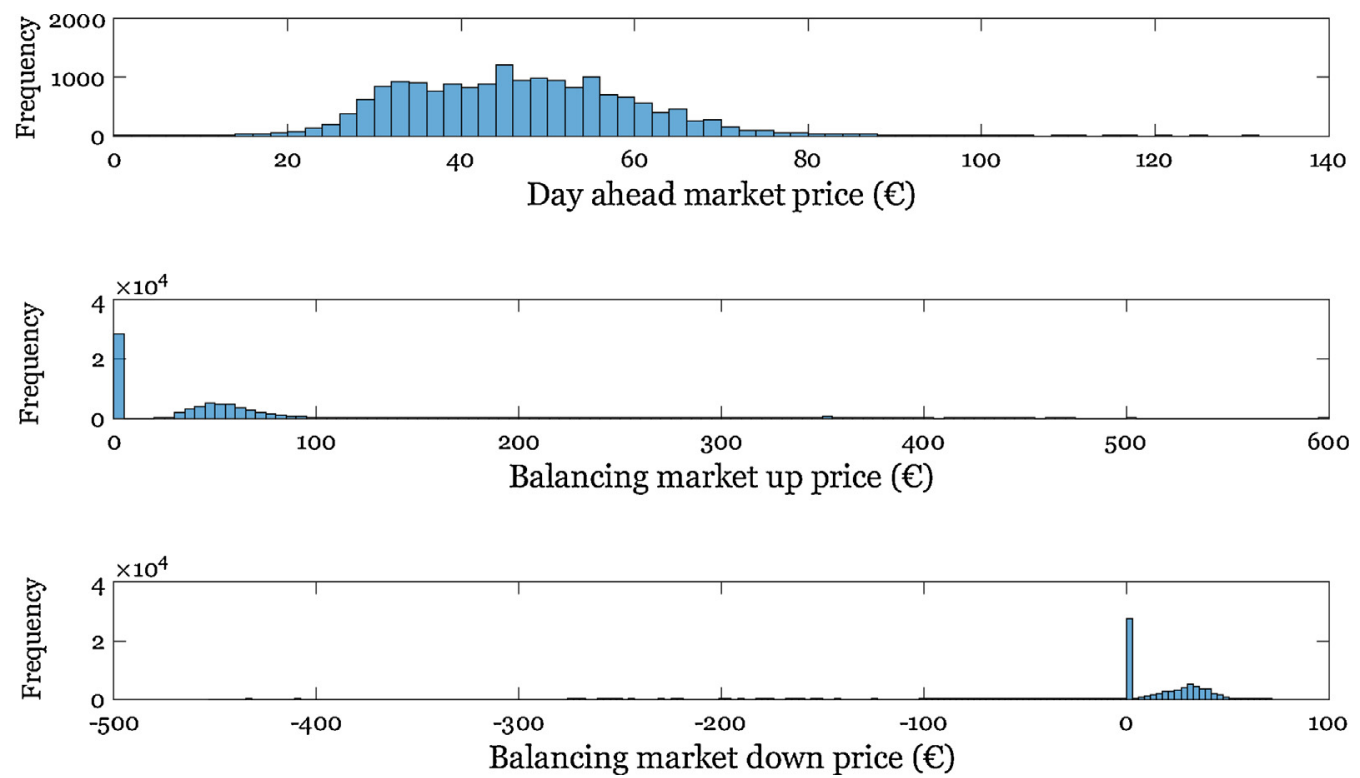

Fig. 2. Price histogram for the day-ahead market prices and balancing market upward and downward prices for 2014 . Each bin has a range size of $2 €$.
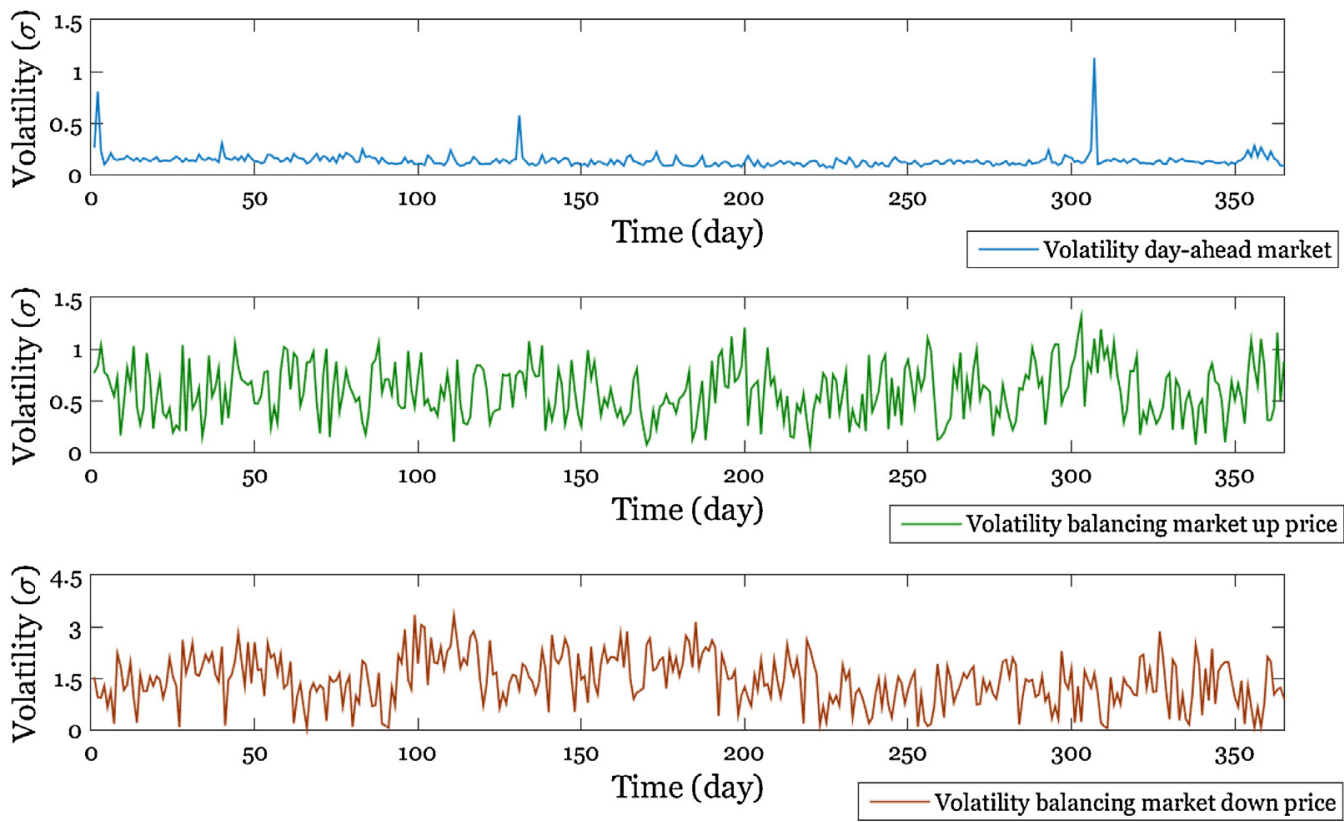

Fig. 3. Volatility towards previous time slot (hour or PTU, depending on the market) for the 2014 day-ahead and balancing market prices.

thresholds, respectively. The real price thresholds $\pi_{B}^{j, \delta}$ and $\pi_{S}^{j, \delta}$, which are the maximal buying and minimal selling prices, respectively, are calculated as follows:

$\pi_{B}^{j, \delta}=\frac{\sum_{t_{j} \in T_{j}} \sum_{m^{j, \delta, t_{j} \in M^{j}}} p_{B}^{j, \delta, t_{j}, m^{j, \delta, t_{j}}}}{n_{T_{j}}^{m_{j}, \delta, t_{j}}} \cdot\left(1-h_{B}^{j, k(\delta)}\right)$,

$\pi_{S}^{j, \delta}=\frac{\sum_{t_{j} \in T_{j}} \sum_{m^{j, \delta, t_{j} \in M^{j}}} p_{S}^{j, \delta, t_{j}, m^{j, \delta, t_{j}}}}{n_{T_{j}}^{m^{j, \delta, t_{j}}}} \cdot\left(1+h_{S}^{j, k(\delta)}\right)$,

where $k(\delta)= \begin{cases}1, & \text { if } \bmod (\delta, 7) \in\{1,2,3,4,5\}, \\ 2, & \text { otherwise. }\end{cases}$
Market 1 is always in the same mode 0, i.e., $M^{1}=0$, while $M^{2}=\{-1$, $0,1,2\}$ (see Table 3 for overview of these modes). In mode $m^{2, \delta, t_{2}}=2$ only one action (buying or selling) is allowed for device 2 . We assume that in such a situation device 2 sells, because selling is more advantageous for the energy storage owner, as shown in [17]. Due to the efficiency losses in charging and discharging, one has to buy more electricity than it can be physically charged into a device and, similarly, one has to discharge more electricity than the amount of energy sold:

$q_{B}^{j, \delta, t_{j}, m^{j, \delta, t_{j}}}=\frac{q_{C}^{j, \delta, t_{j}, m^{j, \delta, t_{j}}}}{\eta_{C}^{j}}, \quad q_{S}^{j, \delta, t_{j}, m^{j, \delta, t_{j}}}=q_{D}^{j, \delta, t_{j}, m^{j, \delta, t_{j}}} \cdot \eta_{D}^{j}$,

where $\eta_{D}^{j} \in[0,1]$ and $\eta_{C}^{j} \in[0,1]$ refer to the efficiencies of discharging and charging, respectively, and are known a priori. 


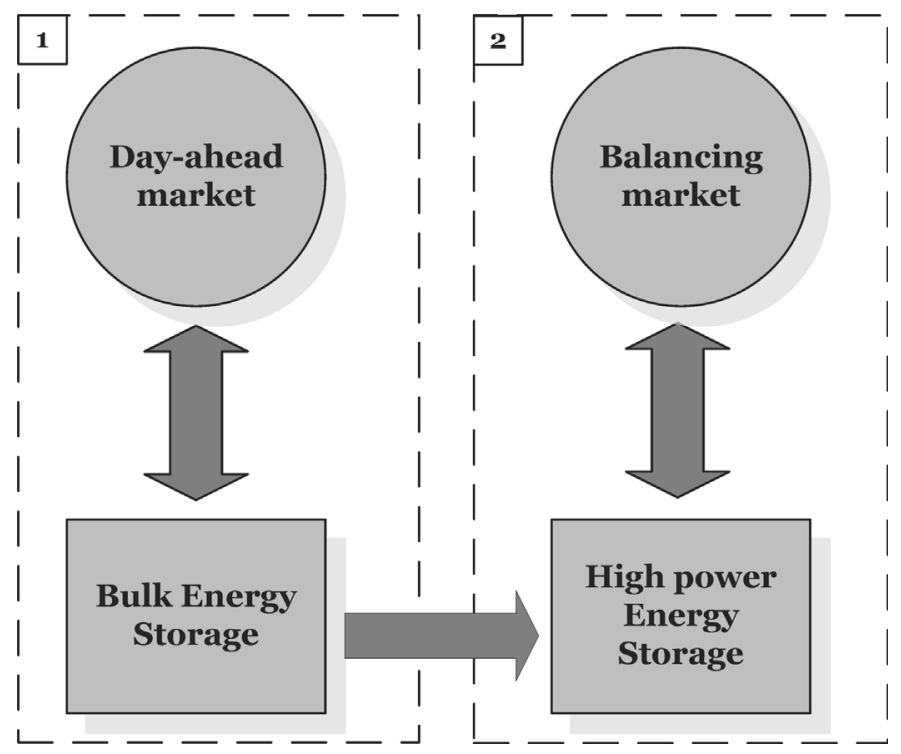

Fig. 4. Illustration of the relationship between the considered energy markets and energy storage devices. The arrows indicate the possible energy transfer directions. The numbers 1 and 2 identify the two partial models.

No device can simultaneously charge and discharge electricity and the amount of electricity charged and discharged cannot exceed its prespecified boundaries, i.e.,

$$
\begin{array}{lll}
q_{C}^{j, \delta, t_{j}, m^{j, \delta, t_{j}}} \cdot q_{D}^{j, \delta, t_{j}, m^{j, \delta, t_{j}}}=0, & q_{C}^{j, \delta, t_{j}, m^{j, \delta, \delta, t_{j}}} \in\left[0, q_{C,}^{j}, \quad \max \quad\right], \\
q_{D}^{j, \delta, t_{j}, m^{j, \delta, t_{j}}} \in\left[0, q_{D,}^{j},\right. & \max \quad] .
\end{array}
$$

As each market/device $j$ can only be in one mode $m^{j, \delta, t_{j}}$ on day $\delta$ and time step $t_{j}$, we set quantities of electricity charged and discharged and their buying and selling prices for all other but the current mode, same day $\delta$ and time step $t_{j}$, to zero:

$q_{C}^{j, \delta, t_{j}, b}=0 \quad \forall b \in M^{j}\left\{m^{j, \delta, t_{j}}\right\}, \quad$ if $\quad q_{C}^{j, \delta, t_{j}, m^{j, \delta, t_{j}}}>0$,

Mode $m^{j, \delta, t_{j}}$ and electricity prices for each market $j$, day $\delta$ and time step $t_{j}$ are exogenous and assumed to be known a priori.

Our model takes advantage of any lower prices in the day-ahead market when compared with the balancing market, by transferring energy from device 1 to device 2 . As device 2 has a time step of $15 \mathrm{~min}$, two complete cycles of charging and discharging may be performed in one hour.

In order to avoid any inconsistency, since device 1 and device 2 are used in our model with different time steps, the energy transferable from one device to another is reserved a priori. This reservation is performed every hour, which is the time step of device 1 and larger of the two time steps. Eq. (11) determines this energy reserved in device 1 transferable to device 2 . As device 1 is much bigger than device 2, device 1 can provide a temporary additional output to charge device 2 when needed:

$$
\begin{aligned}
& \gamma^{1, \delta, t_{1}, m^{1, \delta, t_{1}}} \\
& =\left\{\begin{array}{l}
\frac{2 \cdot q_{C,}^{2} \quad \max }{\eta_{D}^{1} \cdot \eta_{C}^{2}}, \text { if } x^{1, \delta, t_{1}-1, m^{1, \delta, t_{1}-1}+q_{C}^{1, \delta, t_{1}, m^{1, \delta t_{1}}}} \\
\quad \geq \frac{2 \cdot q_{C,}^{2} \quad \max }{\eta_{D}^{1} \cdot \eta_{C}^{2}}+x^{1} \quad \text { min }
\end{array}\right.
\end{aligned}
$$

The energy transfer will only happen when device 2 is not being used in market 2 in the current time step $t_{2}$, as stated in (12). Also, device 2 can only receive energy if it is partially or fully discharged. If so, device 2 will receive the energy from device $1\left(\lambda^{2, \delta, t_{2}, m^{2, \delta, t_{2}}}\right)$. This amount will be the lower of two values: maximum quantity $q_{C}^{2}$ max charged by device 2 or the energy $x^{1, \delta, t_{1}, m^{1, \delta, t_{1}}-x^{1}}$ $\frac{x^{1, \delta, l_{1}, h_{1}}-x^{1}}{\eta_{D}^{1} \cdot \eta_{C}^{2}}$ min that can be transferred to device 2 from device 1. This transfer can occur in every $15 \mathrm{~min}$. For each $t_{2} \in\left\{4 t_{1}-3, \ldots, 4 t_{1}\right\}$,

$$
\begin{aligned}
& \lambda^{2, \delta, t_{2}, m^{2, \delta, t_{2}}} \\
& =\left\{\begin{array}{l}
\min \left(q_{C,}^{2} \max \quad, x^{2} \quad \max -x^{\left.2, \delta, t_{2}-1, m^{2, \delta, t_{2}-1}\right),}\right. \\
\text { if } \gamma^{1, \delta, t_{1}, m^{1, \delta, t_{1}}} \neq 0, \\
q_{C}^{2, \delta, t_{2}, m^{2, \delta, t_{2}}=0} \\
\text { and } q_{D}^{2, \delta, t_{2}, m^{2, \delta, t_{2}}}=0, \\
0, \quad \text { otherwise. }
\end{array}\right.
\end{aligned}
$$

The amount of energy reserved in device 1 not transferred to device 2 is defined as For each $t_{1}=1,2, \ldots$

$\phi^{1, \delta, t_{1}+1, m^{1, \delta, t_{1}+1}}=\gamma^{1, \delta, t_{1}, m^{1, \delta, t_{1}}}-\frac{\sum_{i=1}^{4} \lambda^{2, \delta,\left(t_{1}-1\right) \cdot 4+i, m^{2, \delta,\left(t_{1}-1\right) \cdot 4+i}}}{\eta_{D}^{1} \cdot \eta_{C}^{2}}$.

Here also the losses of discharging device 1 and charging device 2 are taken into consideration. The current state of charge of devices 1 and 2 depends on their state of charge in the previous time step:

$$
\begin{aligned}
x^{1, \delta, t_{1}, m^{1, \delta, t_{1}}}= & x^{1, \delta, t_{1}-1, m^{1, \delta, t_{1}-1}}+q_{C}^{1, \delta, t_{1}, m^{1, \delta, t_{1}}}-q_{D}^{1, \delta, t_{1}, m^{1, \delta, t_{1}}} \\
& -\gamma^{1, \delta, t_{1}, m^{1, \delta, t_{1}}}+\phi^{1, \delta, t_{1}, m^{1, \delta, t_{1}}}
\end{aligned}
$$

$$
\begin{aligned}
x^{2, \delta, t_{2}, m^{2, \delta, t_{2}}}= & x^{2, \delta, t_{2}-1, m^{2, \delta, t_{2}-1}}+q_{C}^{2, \delta, t_{2}, m^{2, \delta, t_{2}}} \\
& -q_{D}^{2, \delta, t_{2}, m^{2, \delta, t_{2}}}+\lambda^{2, \delta, t_{2}, m^{2, \delta, t_{2}}} .
\end{aligned}
$$

When it is not possible to charge or discharge quantities $q_{C}^{1}, \quad \max \quad$ or $q_{D}^{1}, \quad \max$, the device will charge or discharge as much as possible, given by $x^{1} \quad \max -$ $x^{1, \delta, t_{1}-1, m^{1, \delta, t_{1}-1}}$ and $x^{1, \delta, t_{1}-1, m^{1, \delta, t_{1}-1}}-x^{1} \quad \min$, respectively. As most energy storage devices cannot be fully discharged, $x^{j} \quad \min \quad$ represents the minimum useful state of charge, the lowest charge level the storage device can be discharged to. Quantity $q_{D}^{1, m^{1, \delta, t_{1}}, \delta, t_{1}}$ is defined as follows:

$$
\begin{aligned}
& q_{D}^{1, \delta, t_{1}, m^{1, \delta t_{1}}} \\
& =\left\{\begin{array}{l}
\min \left(q_{D,}^{1} \quad \max \quad, x^{1, \delta, t_{1}-1, m^{1, \delta, t_{1}-1}-x^{1}} \min \right), \\
\text { and } p_{S}^{1, \delta, t_{1}, m^{1, \delta, t_{1}}} \geq \pi_{S}^{1, \delta}, \\
0, \quad \text { otherwise. }
\end{array}\right.
\end{aligned}
$$

As device 1 starts discharged, Eq. (16) is only valid for $t_{1} \geq 2$ or when $\delta \geq 2$. Likewise, $q_{C}^{1, m^{1, \delta, t_{1}, \delta, t_{1}}}$ is defined as follows:

$$
\begin{aligned}
& q_{C}^{1, \delta, t_{1}, m^{1, \delta, t_{1}}} \\
& =\left\{\begin{array}{l}
\min \left(q_{C,}^{1},\right. \\
\quad \text { if } p_{B}^{1, \delta, t_{1}, m^{1, \delta, t_{1}}} \leq \pi_{B}^{1, \delta}, \\
0, \quad \text { otherwise. }
\end{array}\right.
\end{aligned}
$$

If device 2 cannot charge the maximum quantity of energy charged $q_{C}^{2}, \quad \max$, as it would overrun the maximum amount of charge $x^{2} \quad \max$, it will charge quantity

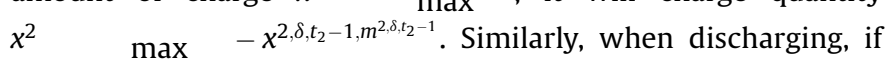


device 2 cannot discharge the maximum quantity of energy discharged $q_{D}^{2}, \quad \max \quad$, as it would overrun the functional minimum amount of charge $x^{2} \quad \min$, it will charge the quantity $x^{2, \delta, t_{2}-1, m^{2, \delta, t_{2}-1}}-x^{2} \quad \min$.

$$
q_{D}^{2, \delta, t_{2}, m^{2, \delta, t_{2}}}
$$

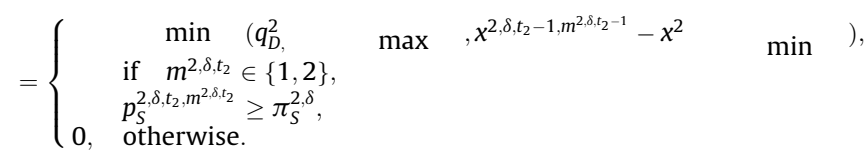

$$
\begin{aligned}
& q_{C}^{2, \delta, t_{2}, m^{2, \delta, t_{2}}}
\end{aligned}
$$

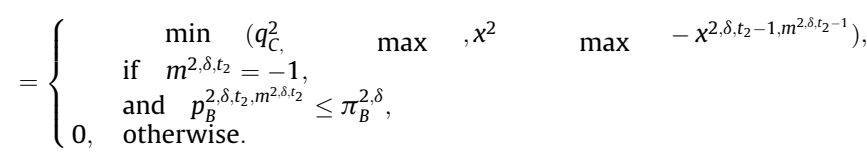

As device 2 starts discharged, Eq. (18) is only valid only for $t_{2} \geq 2$ or when $\delta \geq 2$.

The maximum discharge capacity $q_{D, \max }^{1}$ of device 1 is lower or equal to its maximum state of charge $x^{1} \quad \max$ minus the transferable energy to device $2 \frac{2 \cdot q_{C}^{2} \quad \max }{\eta_{D}^{1} \cdot \eta_{C}^{2}}$ :

$\begin{array}{rlr}q_{D,}^{1} \quad \max & \leq x^{1} \quad \max \\ & -\frac{2 \cdot q_{C}^{2},}{\eta_{D}^{1} \cdot \eta_{C}^{2}} .\end{array}$

Other constraints:

$q_{C, \text { max }}^{j} \leq x^{j} \quad \max \quad$,

$q_{D,}^{2} \quad \max \leq x^{2} \quad \max$,

$q_{D,}^{j} \quad \min \quad=q_{C,}^{j}, \quad \min =0$,

$0 \leq x^{j} \quad \min \quad \leq x^{j} \quad \max$

Initial conditions:

$\chi^{j, 1,0, m^{j, 1,0}}=0$,

$\phi^{1,1,1, m^{1,1,1}}=0$.

In words, the problem (1), subject to (2)-(26), is to find the selling and buying threshold prices per day in a week, for each device type/market, so that the revenue of the entire storage system device is maximized.

\section{Implementation}

In this section we describe the implementation of the model and optimal price thresholds, given by (1)-(26). The technical and economical data on the devices are taken from [11]. All case studies defined by equations were implemented using Matlab ${ }^{\circledR}$.

The problem (1)-(26) could not be solved by standard optimization techniques, such as gradient-based optimization methods, due to many local minima and even regions in the domain of the yearly benefit function which correspond to the same benefit value. After experimenting with heuristic solution methods, such as particle swarm optimization (PSO), we have adopted a pattern search (PS) algorithm included in the Matlab optimization toolbox for solving the problem. The main advantages of PS are its speed and the fact that it does not use gradient approximation to maximize the profit function. Therefore, PS is often used for maximizing complicated functions which are nonsmooth or even discontinuous and/or have many local minima. The method was first proposed in the literature by [25] and is extensively described in [26].

Algorithm for solving the problem (1)-(26) is depicted in Fig. 5. For comparison purposes we also calculated the results when using a single weekly set of price thresholds per device, using the algorithm depicted in Fig. 6.

We assume that both devices can be fully discharged $\left(x_{j, \min }=0\right)$ and start discharged $\left(x^{j, 1,0, m^{j, 1,0}}=0\right)$. No self-discharge was considered as the devices are working almost continuously. Ramp rates were also not considered.

\section{Results}

\subsection{Finding optimal price thresholds}

We have calculated the solution to the problem (1)-(26) for year 2014 using the pattern search introduced in Section 3. For 2014, the optimal $u^{*}$ contains price thresholds depicted in Fig. 7.

The generic bulk energy storage power rating is varied between 50 and $150 \mathrm{MW}$ for a discharge duration of 5-10 h. The energy rating varies between 500 and $1500 \mathrm{MWh}$. The power rating is the maximum amount of energy that the device can charge or discharge in one hour. Unless mentioned otherwise, the round trip efficiency is $80 \%=0.80$, and the charging and discharging efficiencies are equal to $\sqrt{0.8}(\approx 0.8944=89.44 \%)$. The electricity market data used to evaluate the profitability of this device is Dutch dayahead market data provided by the spot market APX-Endex.

For the high-power device, the power rating is varied between 20 and $60 \mathrm{MW}$. The nominal discharge duration is of 15 minutes. As energy rating of the device is calculated as its power rating multiplied by its time of discharge of that same device, the energy rating will vary from 5 to $15 \mathrm{MWh}$. Therefore, this energy rating interval $[5,15]$ MWh was selected as the base power rating of device 2 . The minimum bid size for the Dutch balancing market is 5 MW [20] per PTU of 15 minutes. The default charging and discharging efficiencies of this device are both $95 \%$ (0.95), which results in a round trip efficiency of around 90\% (0.90). The balancing market data is publicly available from the Dutch TSO TenneT [28]. The dimensions and efficiency levels of both devices are chosen according to technologies described in [11]. Fig. 7 shows the solution to the problem (1)-(26) when two sets of thresholds are applied. The size of the bulk and the high power devices in this example are $50 \mathrm{MW}, 500 \mathrm{MWh}$ and $20 \mathrm{MW}, 5 \mathrm{MWh}$, respectively. There, different results can be observed for weekdays and weekends. For the day-ahead market and bulk device, weekend thresholds are usually lower. For the balancing market and high power device, the difference is bigger. In this case, the yearly benefit is the highest when the high power device is used to buy less in the weekends and when it sells more during the working days than in the weekends.

However, it was realized that the improvement towards a single set of thresholds was limited $(0.2-1.1 \%)$ and the computational time was at least doubled. This is possibly due to the weekend prices being usually lower than the ones of the working days and that their volatility is lower than volatility of the prices for working 


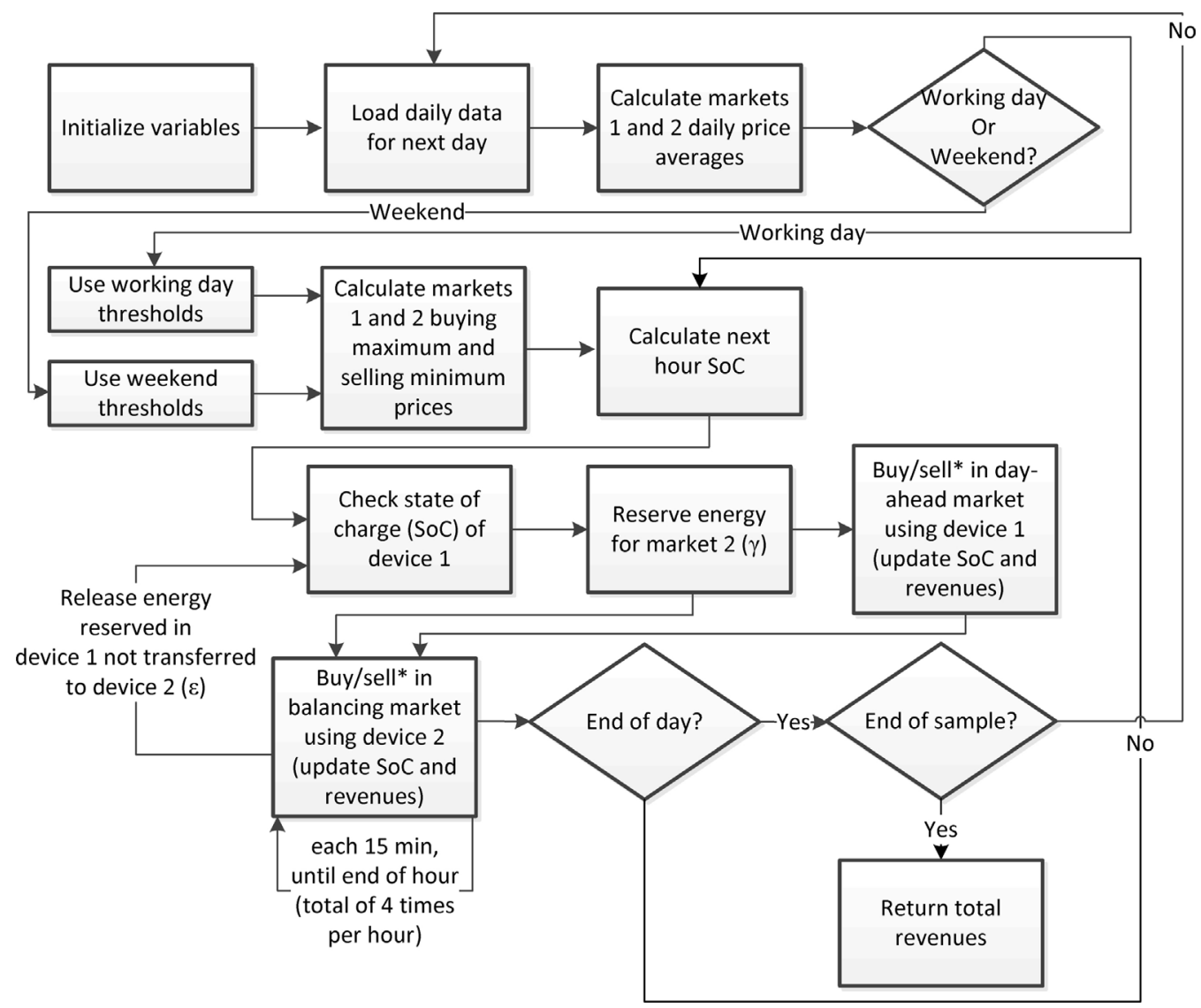

*: The device will charge, discharge or do nothing according to the price and the market mode on that timeslot and the buying / selling thresholds defined for that day

Fig. 5. Representation of the algorithm solving the problem (1)-(26).

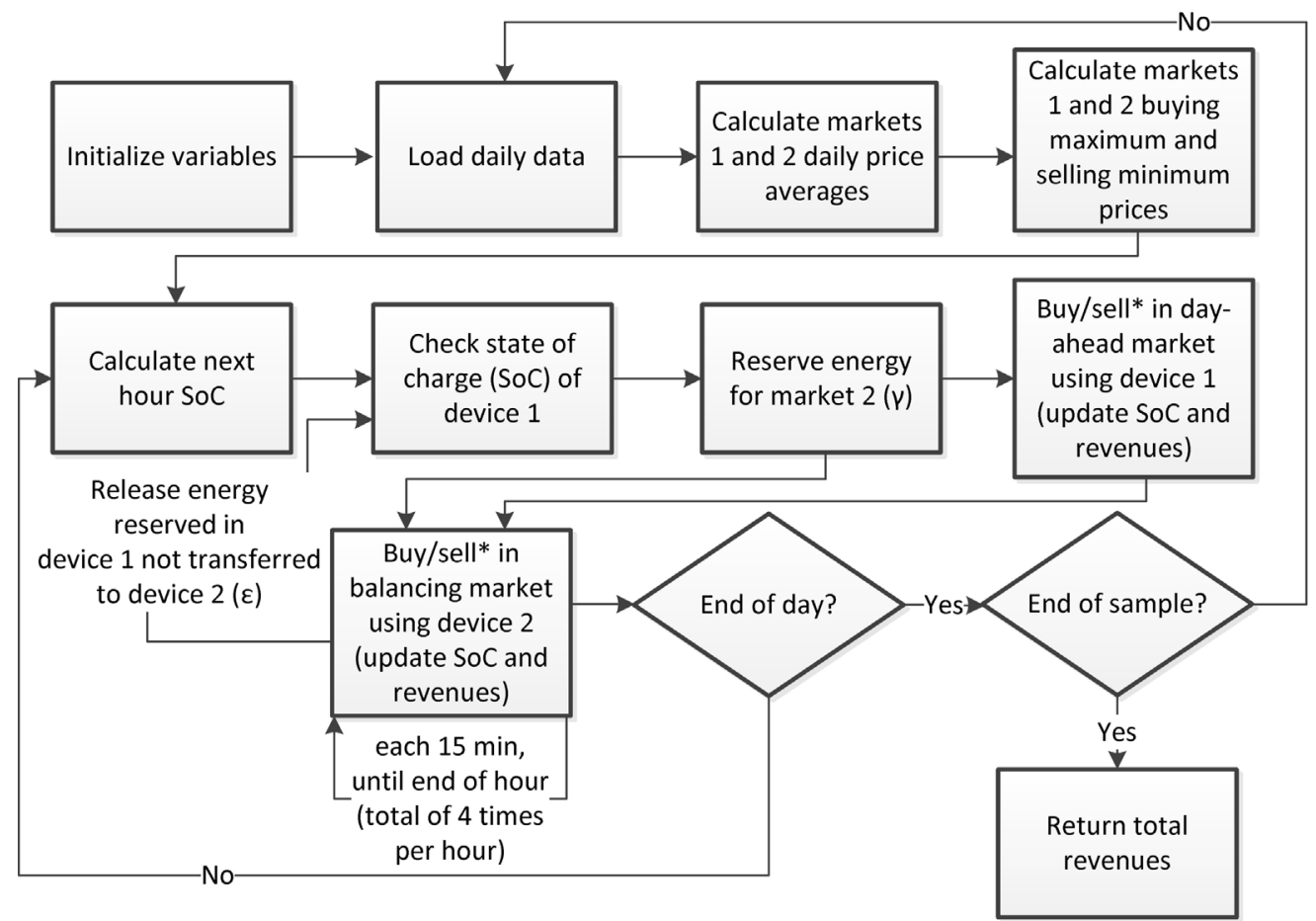

*: The device will charge, discharge or do nothing according to the price and the market mode on that timeslot and the buying / selling thresholds defined for that day

Fig. 6. Representation of the algorithm solving the problem (1)-(26) with the same weekend and working days price thresholds. 


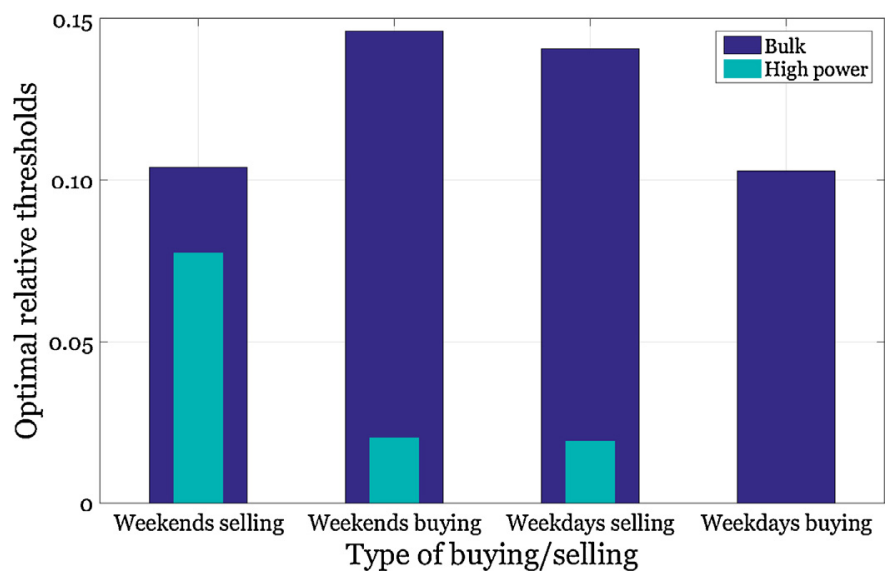

Fig. 7. Optimal relative thresholds. The value of the selling thresholds indicates how much above the daily mean selling price the electricity will be sold, while the value of the of the buying thresholds indicates how much below the daily mean buying price the electricity will be bought. Device sizes are $50 \mathrm{MW}, 500 \mathrm{MWh}$ and $20 \mathrm{MW}$, $5 \mathrm{MWh}$, for the bulk and the high power device, respectively. The optimal working day (written as "weekdays" in the caption) buying threshold for the high power device is zero. The yearly benefit with this set of thresholds is $2.615 \mathrm{M} €$.

days. Therefore, less opportunities for the devices to be active in the respective markets. These situations can also be observed in Fig. 1 and in Fig. 3, particularly for the day-ahead market. Due to this limited improvement of yearly benefit when having variable selling and buying thresholds for working days and weekends, we will use the single set of thresholds for the rest of the paper.

Using data from 2014, we have calculated the revenues when varying the rating of both devices see Fig. 8 . Here " $50 \cdot 10^{\prime \prime}$ refers to a device with a nominal power rating of $50 \mathrm{MW}$ and a discharge duration of $10 \mathrm{~h}$. Increasing the size of the bulk device three times (high power device of $5 \mathrm{MWh}$, bulk device of $150 \mathrm{MW}$ and $10 \mathrm{~h}$ of discharge time) and increasing the size of the high-power device (high power device of $15 \mathrm{MWh}$, bulk device of $50 \mathrm{MW}$ and $10 \mathrm{~h}$ of discharge time) have almost the same impact on the yearly benefit, when compared with the base situation (high power device of $5 \mathrm{MWh}$, bulk device of $50 \mathrm{MW}$ and $10 \mathrm{~h}$ of discharge time). This is an interesting observation for eventual practical applications, as the costs for increasing the size of the two devices can be different.
For comparison purposes, we have calculated the revenues using only the bulk energy device. The result is shown in Fig. 9. Clearly, the power rating has a higher impact on the yearly benefit when compared to the impact of energy rating. The two left bars correspond to the same energy rating (500 MWh) and two different power ratings (50 MW and $100 \mathrm{MW}$, respectively).

Fig. 10 shows that the yearly benefit increase when moving from the situation with a single device (Fig. 9) to the situation with the dual energy storage system (Fig. 8). The highest increase of the yearly benefit is for the bulk device with the lowest power and energy rating ( $50 \mathrm{MW}$ and $500 \mathrm{MWh}$ ). With this bulk device, including a high power (HP) device of 5,10 , and $15 \mathrm{MWh}$ leads to the yearly benefit increase of $85 \%, 170 \%$, and $256 \%$, respectively.

Fig. 11 compares the yearly benefits when using only the bulk device and the two devices, respectively, for several device sizes and with price data from 2014. The four subfigures display different yearly benefit distribution between the devices: For the first case (bulk: $100 \mathrm{MW} \cdot 10 \mathrm{~h}, \mathrm{HP}$ : $5 \mathrm{MWh}$ ), the bulk device operating on the day-ahead market (device and market 1) obtains $56.03 \%$ of the yearly benefit, while the high-power device operating on the balancing market (device and market 2) obtains $43.97 \%$ of the yearly benefit. The yearly benefit of device 1 is lower than in a stand-alone situation, due to energy transferred from device 1 to device 2 . The lower bar shows the yearly benefit when only the bulk device operating in the day-ahead market is used. The comparison of the two bars indicates that by combining devices 1 and 2 , the yearly benefit in the day-ahead market is reduced by $20.05 \%$, while the total yearly benefit increases by 42.69\%. For the last case (bulk: $50 \mathrm{MW} \cdot 10 \mathrm{~h}, \mathrm{HP}: 15 \mathrm{MWh}$ ), a reduction by $110.95 \%$ in the day-ahead market yearly benefit (a net loss of $10.95 \%$ ) and an increase of $255.96 \%$ in the total yearly benefit can be observed. The results for the examples from Fig. 11 are shown in Table 4.

Additionally, we have analysed the impact of round trip efficiency of both devices on the results, see Fig. 12. The device ratings are $50 \mathrm{MW}$ and $500 \mathrm{MWh}$ for the bulk device and $20 \mathrm{MW}$ and $5 \mathrm{MWh}$ for the high-power device, respectively. The charging and discharging efficiencies are assumed to be the same and equal to the square root of the round trip energy efficiency. Fig. 12 illustrates that the efficiency of the bulk device has a greater impact on the yearly benefit than the efficiency of the high power device.
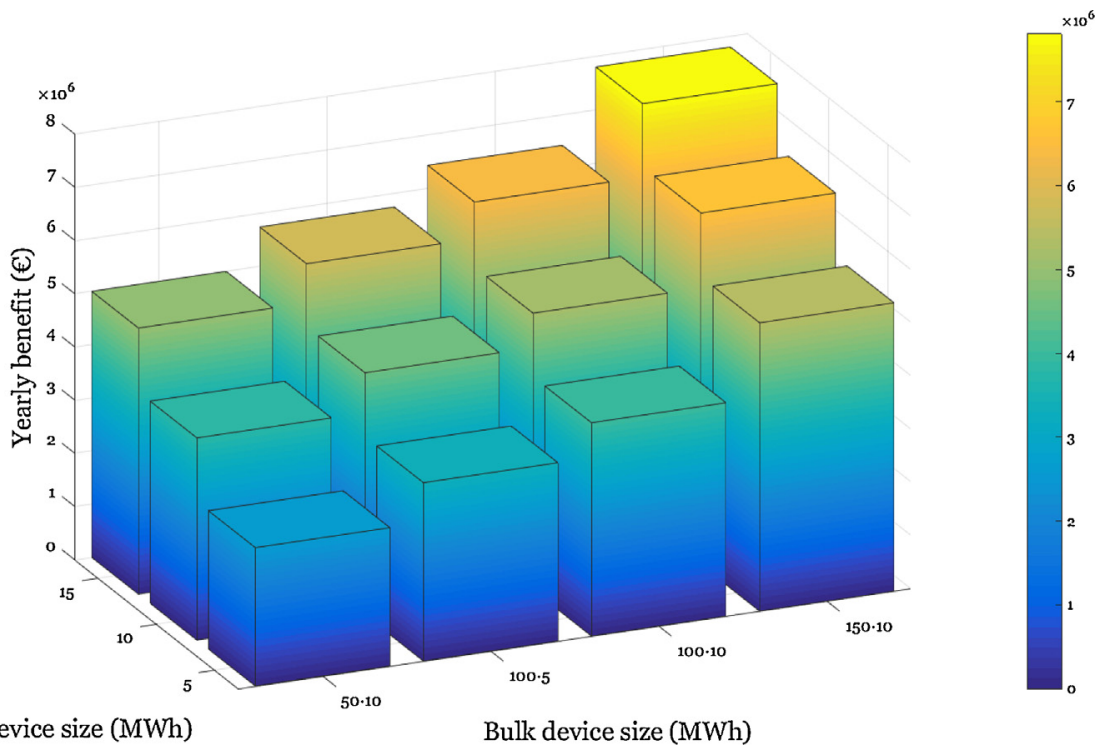

High power device size (MWh)

Bulk device size (MWh)

Fig. 8. Yearly benefit when varying the size of the two devices. 


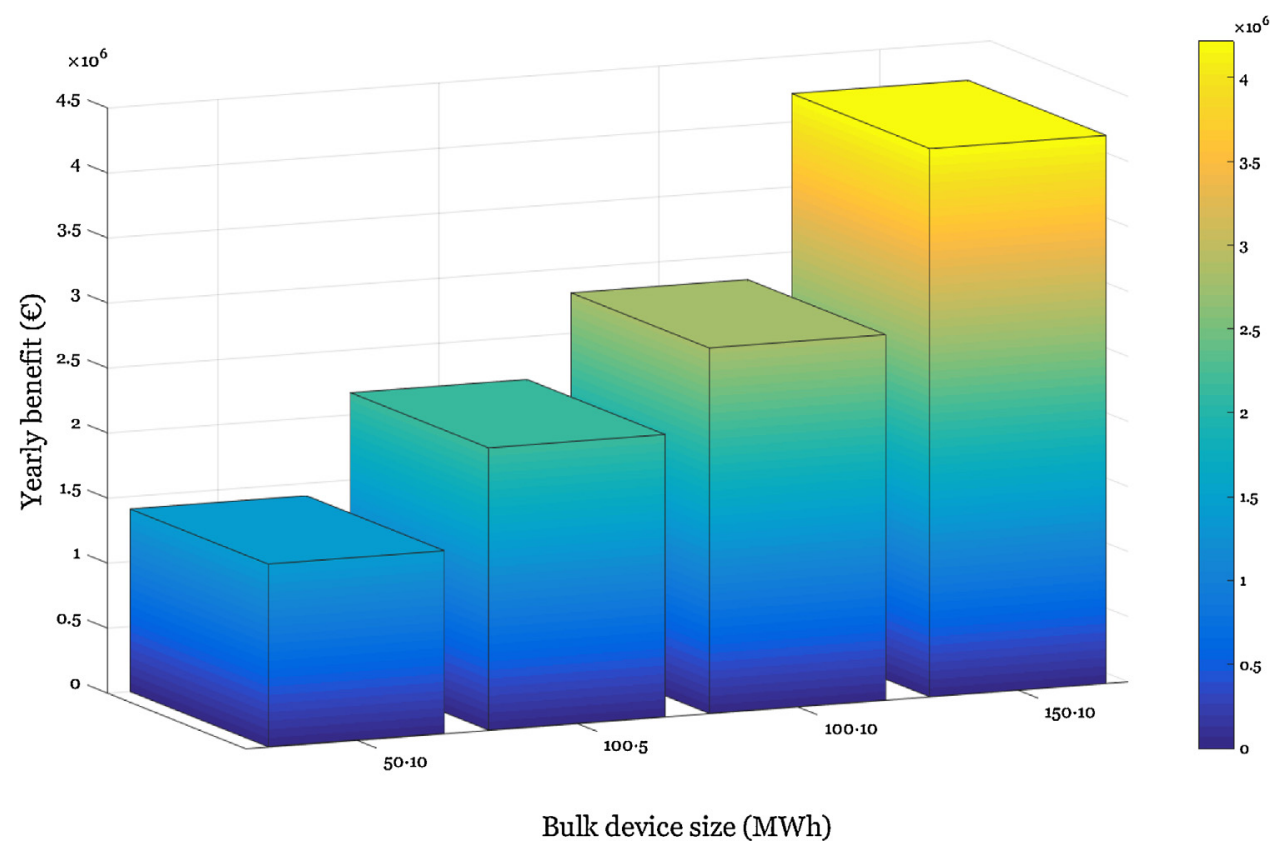

Fig. 9. Revenues using only the bulk device and data from 2014.

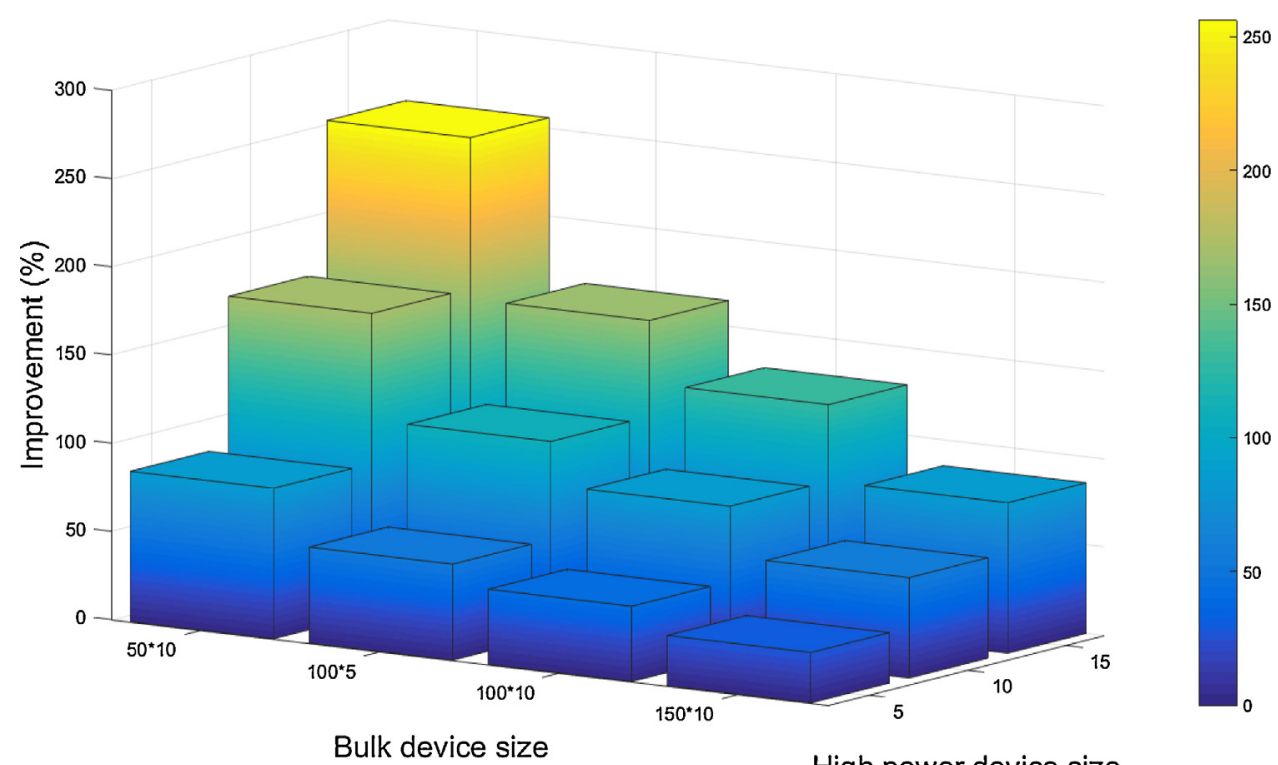

Fig. 10. Revenues increase (in \%) from using only the bulk device to two devices.

Furthermore, we have analysed the impact of using energy prices from the years 2012 and 2013 on the model predictions and compared them to those with the 2014 prices. Fig. 13 shows the results for a bulk device of $50 \mathrm{MW}$ and $500 \mathrm{MWh}$ and a comparison between the high power devices of $20 \mathrm{MW}, 5 \mathrm{MWh}$ and of $40 \mathrm{MW}$, $10 \mathrm{MWh}$. Round trip efficiencies are $70 \%$ and $90 \%$ for the bulk and the high-power devices, respectively. The volatilities towards the previous time slot for the 2012 and 2013 electricity prices are shown in Appendix A. The yearly benefit for 2014 are below the average yearly benefit of two years before.

\subsection{Cost-benefit analysis for different energy storage devices}

Here we focus on calculating of the payback period (PBP) for using the ESS, depending on which particular ESS is used. The PBP $(\psi)$ is calculated by dividing the initial investment by the yearly net revenues [30] as shown in Eq. (28). In order to increase the accuracy of this study, we have used price data from years 2012, 2013 and 2014. ${ }^{3}$ The costs of the devices used to calculate the initial investment are taken from [11]. The costs per unit of power $(\mathrm{kW})$ and unit of energy $(\mathrm{kWh})$ of device $j$ are denoted by $\mu^{j}$ and $\xi^{j}$, respectively. The power and energy ratings for a device $j$ are denoted by $\rho^{j}$ and $\varepsilon^{j}$, respectively. The Euro/Dollar conversion rate

\footnotetext{
${ }^{3}$ Other approaches could be used such as the one presented by [29], where energy storage device optimal sizing for arbitrage provision is evaluated.
} 

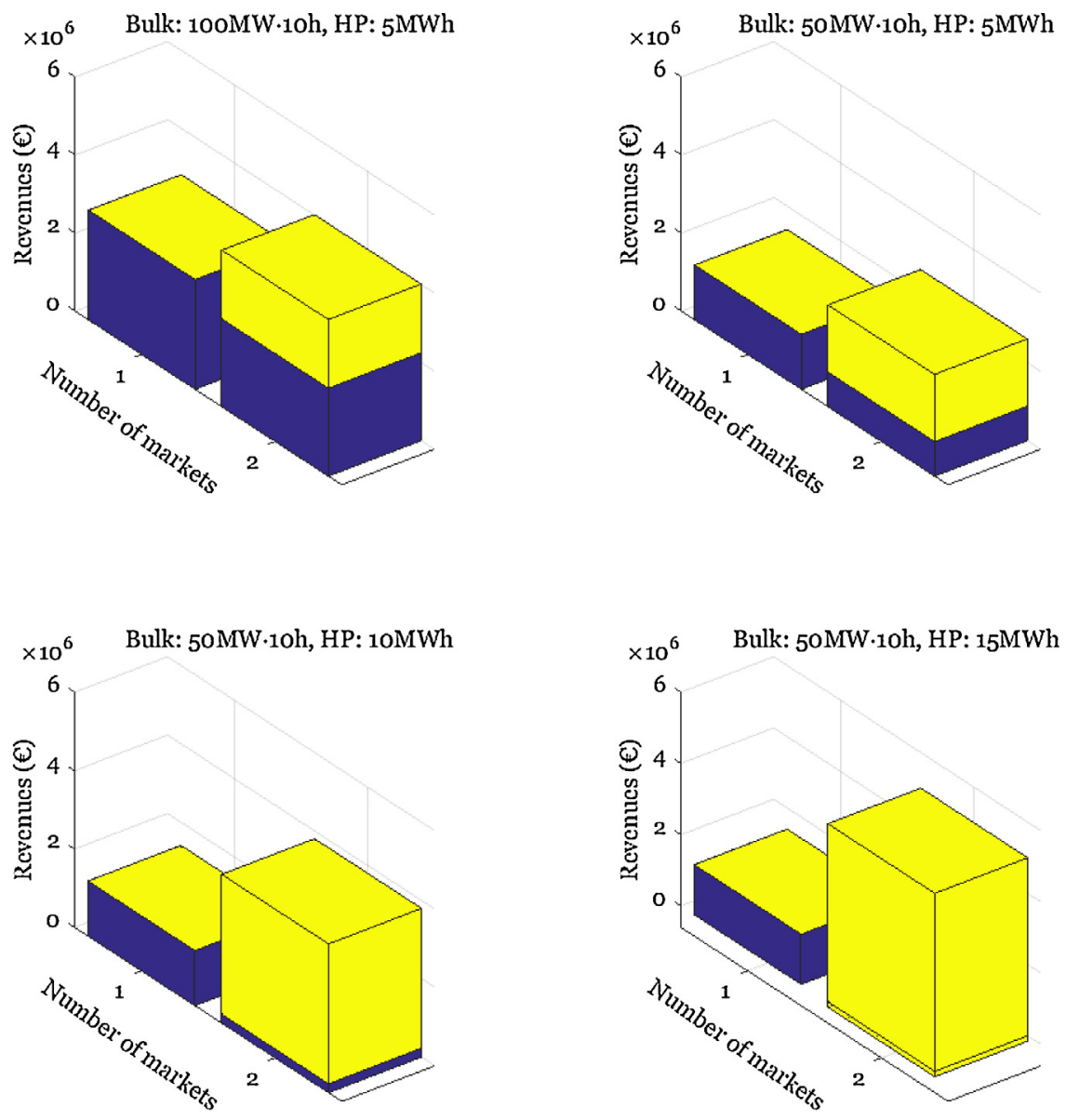

Fig. 11. Yearly benefit distribution for the results mentioned in Table 4, when using dual and single ESS.

Table 4

Results for the examples shown in Fig. 11.

\begin{tabular}{llllll}
\hline $\begin{array}{l}\text { Bulk } \\
\text { size }\end{array}$ & $\begin{array}{l}\text { HP } \\
\text { size }\end{array}$ & $\begin{array}{l}\text { Bulk share } \\
(\%)\end{array}$ & $\begin{array}{l}\text { HP share } \\
(\%)\end{array}$ & $\begin{array}{l}\text { Bulk variation to } \\
\text { standalone (\%) }\end{array}$ & $\begin{array}{l}\text { Overall } \\
\text { increase (\%) }\end{array}$ \\
\hline $100 \mathrm{MW} \cdot 10 \mathrm{~h}$ & $5 \mathrm{MWh}$ & $56.03 \%$ & $43.97 \%$ & $-20.05 \%$ & $42.69 \%$ \\
$50 \mathrm{MW} \cdot 10 \mathrm{~h}$ & $5 \mathrm{MWh}$ & $33.87 \%$ & $66.13 \%$ & $-37.26 \%$ & $85.26 \%$ \\
$50 \mathrm{MW} \cdot 10 \mathrm{~h}$ & $10 \mathrm{MWh}$ & $5.93 \%$ & $94.07 \%$ & $-83.97 \%$ & $170.45 \%$ \\
$50 \mathrm{MW} \cdot 10 \mathrm{~h}$ & $15 \mathrm{MWh}$ & $-3.08 \%$ & $103.08 \%$ & $-110.95 \%$ & $255.96 \%$ \\
\hline
\end{tabular}

is $1 / 1.10$, following the information provided in [27]. The yearly benefit $Z(u)$ is replaced by $Z^{\prime}(u)$ defined as ${ }^{4}$

$$
\begin{aligned}
\sum_{j \in J} \sum_{\delta \in D} \sum_{t_{j} \in T_{j}} \sum_{m^{j, \delta, t_{j}} \in M^{j}} & \left(q_{S}^{j, \delta, t_{j}, m^{j, \delta, t_{j}}} \cdot\left(p_{S}^{j, \delta, t_{j}, m^{j, \delta, t_{j}}}-\kappa^{j}\right)\right. \\
& \left.-q_{B}^{j, \delta, t_{j}, m^{j, \delta, t_{j}}} \cdot p_{B}^{j, \delta, t_{j}, m^{j, \delta, t_{j}}}\right),
\end{aligned}
$$

which takes the variable the variable $0 \& M$ costs $\kappa^{j}$ per unit of energy for device $j$ into account.

The yearly net benefit is calculated by subtracting the yearly operation and maintenance costs $o^{j}$ from the optimal yearly benefit $Z^{\prime}\left(u^{*}\right)$. Furthermore, we compare the payback period $\psi$ defined as

$\psi=\frac{\sum_{j \in J}\left(\rho^{j} \cdot \mu^{j}+\varepsilon^{j} \cdot \xi^{j}\right)}{Z^{\prime}\left(u^{*}\right)-\sum_{j \in J} o^{j}}$.

for the years 2012-2014 with those of 2014 .

\footnotetext{
${ }^{4}$ With a slight abuse of notation as $u$ maximizing $Z^{\prime}(u)$ will differ from original $u *$
} maximizing $Z(u)$
The internal rate of return $\iota$ is used to calculate the profitability of potential investments in the ESS and is calculated for a certain prespecified number of years $n_{Y}$, so that equality

$\sum_{y=0}^{n_{Y}} \frac{Z^{\prime}\left(u^{*}\right)-\sum_{j \in J} o^{j}}{(1+\iota)^{n}}-\sum_{j \in J}\left(\rho^{j} \cdot \mu^{j}+\varepsilon^{j} \cdot \xi^{j}\right)=0$

is satisfied. In the two case studies to follow, we will discuss $\iota$ calculated for $N=10,15$ and 20 years. We will also compare $\iota$ obtained with average of values for $Z^{\prime}\left(u^{*}\right)$ and $o^{j}$ over years 20122014 with those from 2014 only. As in these case studies we will vary technologies used for the ESS, in Appendix B we discuss in detail the technologies available.

\subsubsection{Case study 1: Cost benefit analysis with D-CAES and Li-ion battery technologies}

For the first case study a traditional D-CAES of $50 \mathrm{MW}$ and $500 \mathrm{MWh}$ is used as the bulk device. A Li-ion battery (LI) technology of $10 \mathrm{MWh}$ was selected as the high power device. The round trip efficiencies are $50 \%$ and $85 \%$ for the D-CAES and for the LI, respectively, as reported in [11]. For D-CAES, the minimum costs $\mu^{1}$ and $\xi^{1}$ are $3.64 \cdot 10^{5} € / \mathrm{MW}$ and $1.82 \cdot 10^{3} € / \mathrm{MWh}$ respectively. For LI, $\mu^{2}$ and $\xi^{2}$ are $1.09 \cdot 10^{6} € / \mathrm{MW}$ and $5.45 \cdot 10^{5} € / \mathrm{MWh}$, respectively [11]. Operation and maintenance costs are the average values presented in [31]. For LI the fixed O\&M costs are $6.9 € / \mathrm{KW}$-yr and the variable costs are $2.1 € / \mathrm{MWh}$. For the $\mathrm{D}$-CAES, the fixed O\&M costs are $3.9 € / K W$-yr and the variable costs are $3.1 € / \mathrm{MWh}$.

Table 5 shows the results of the cost benefit analysis. The internal rate of return $\iota$ was calculated for average yearly benefit 


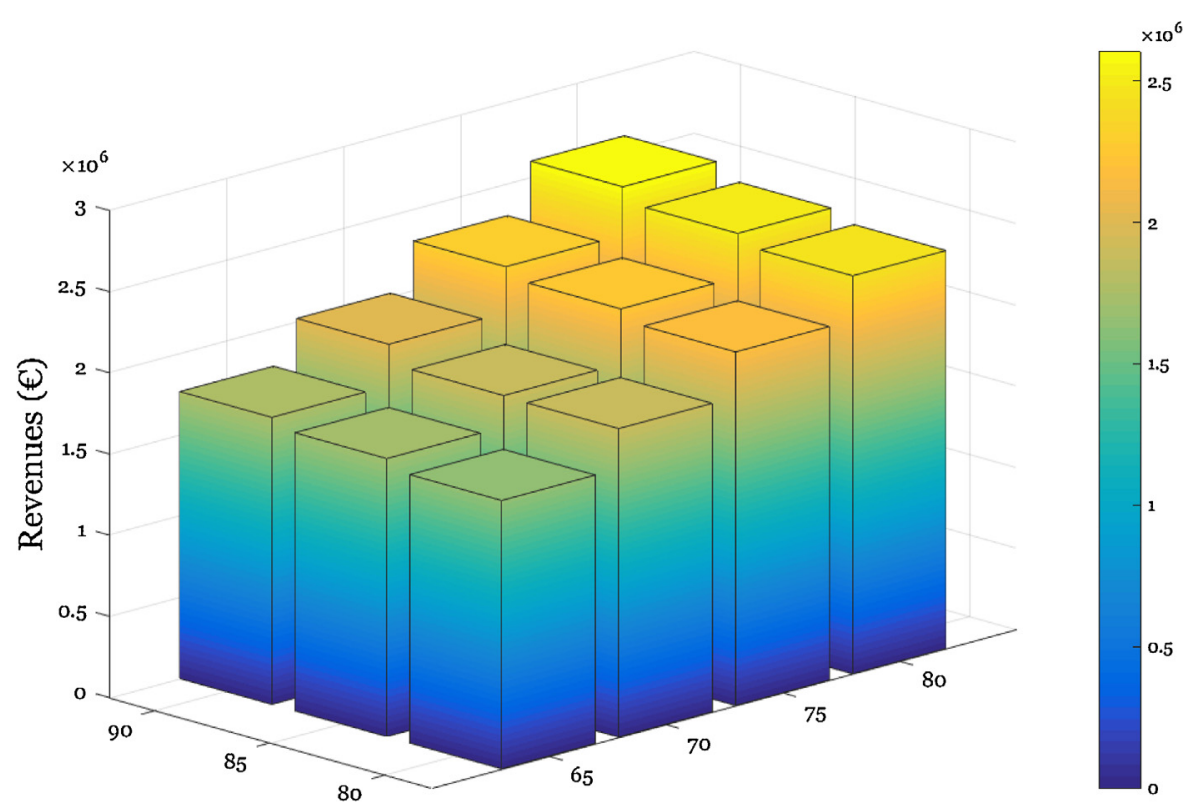

High power device efficiency (\%) Bulk device efficiency (\%)

Fig. 12. Impact on the results of efficiency of the devices. Size of the devices used for the bulk device: $50 \mathrm{MW}$ and $500 \mathrm{MWh}$, for high power: $20 \mathrm{MW}$ and $5 \mathrm{MWh}$

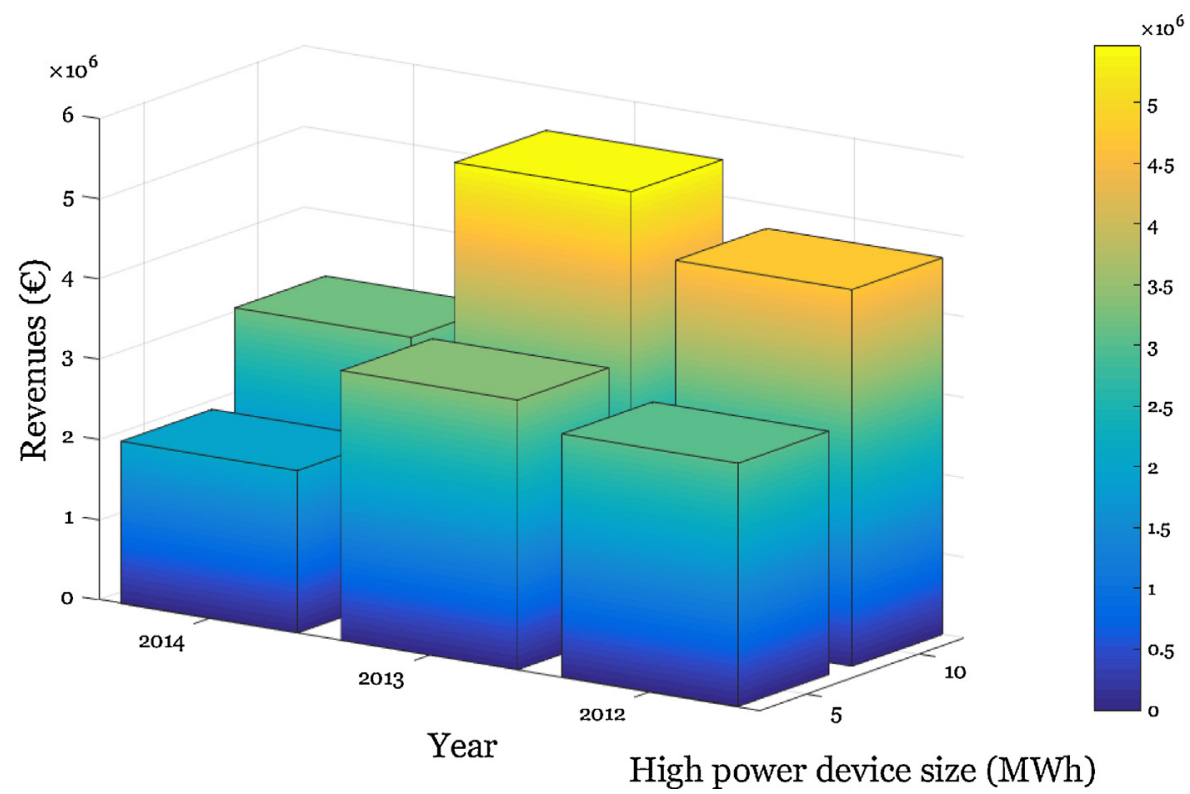

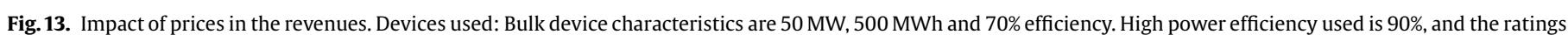
used are $20 \mathrm{MW}, 5 \mathrm{MWh}$ and $40 \mathrm{MW}, 10 \mathrm{MWh}$.

over years 2012-2014 (see Fig. 14 for the yearly benefits and its average) and for 20,15 and 10 years. The payback period $\psi$ was calculated for the average yearly benefit from years 2012-2014 and also when the lowest yearly benefit of these 3 years was considered (year 2014). These results show that this system will take more than 17 years to be paid back when considering average year benefits over years 2012-2014. For this case study, $\iota$ (IRR) in the first 20 years will be slightly positive (1\%). Using the values of 2014, it will take almost 27 years for the devices to be paid and $\iota$ will be negative in all the situations analysed.
6.2.2. Case study 2: Cost benefit analysis with AACAES and flywheel technologies

For the second case study a AACAES of $50 \mathrm{MW}$ and $500 \mathrm{MWh}$ is used as bulk device, while a flywheel (FW) technology of $15 \mathrm{MWh}$ was selected as a high power device. The round trip efficiencies are $70 \%$ and $90 \%$ for the AACAES and for the FW, respectively [11]. For AACAES, the costs considered are $40 \%$ higher than the costs of DCAES, following [31]. Therefore, the minimum costs $\mu^{1}$ and $\xi^{1}$ are $5.09 \cdot 10^{5} € / \mathrm{MW}$ and $2.55 \cdot 10^{3} € / \mathrm{MWh}$, respectively. For FW, $\mu^{2}$ and $\xi^{2}$ are $2.27 \cdot 10^{5} € / \mathrm{MW}$ and $9.1 \cdot 10^{5} € / \mathrm{MWh}$, respectively [11]. 


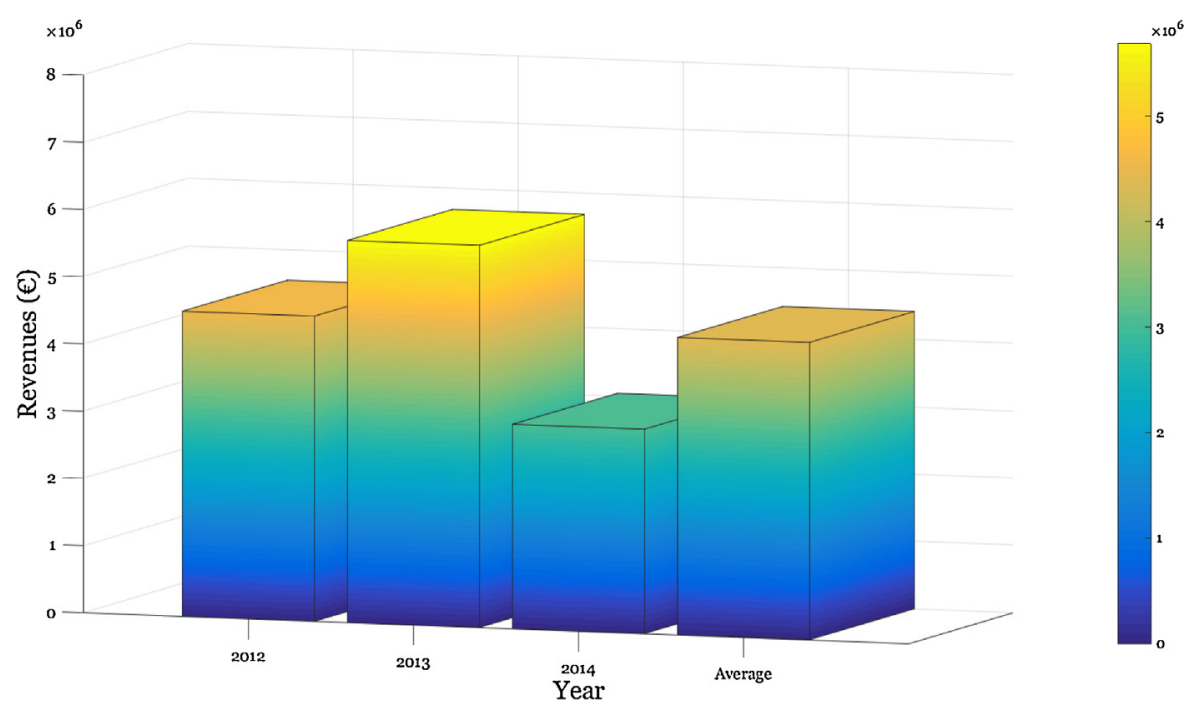

Fig. 14. Results for DCAES $50 \mathrm{MW}, 500 \mathrm{MWh}$ and $50 \%$ efficiency and LI $40 \mathrm{MW}, 10 \mathrm{MWh}$ and efficiency $85 \%$.

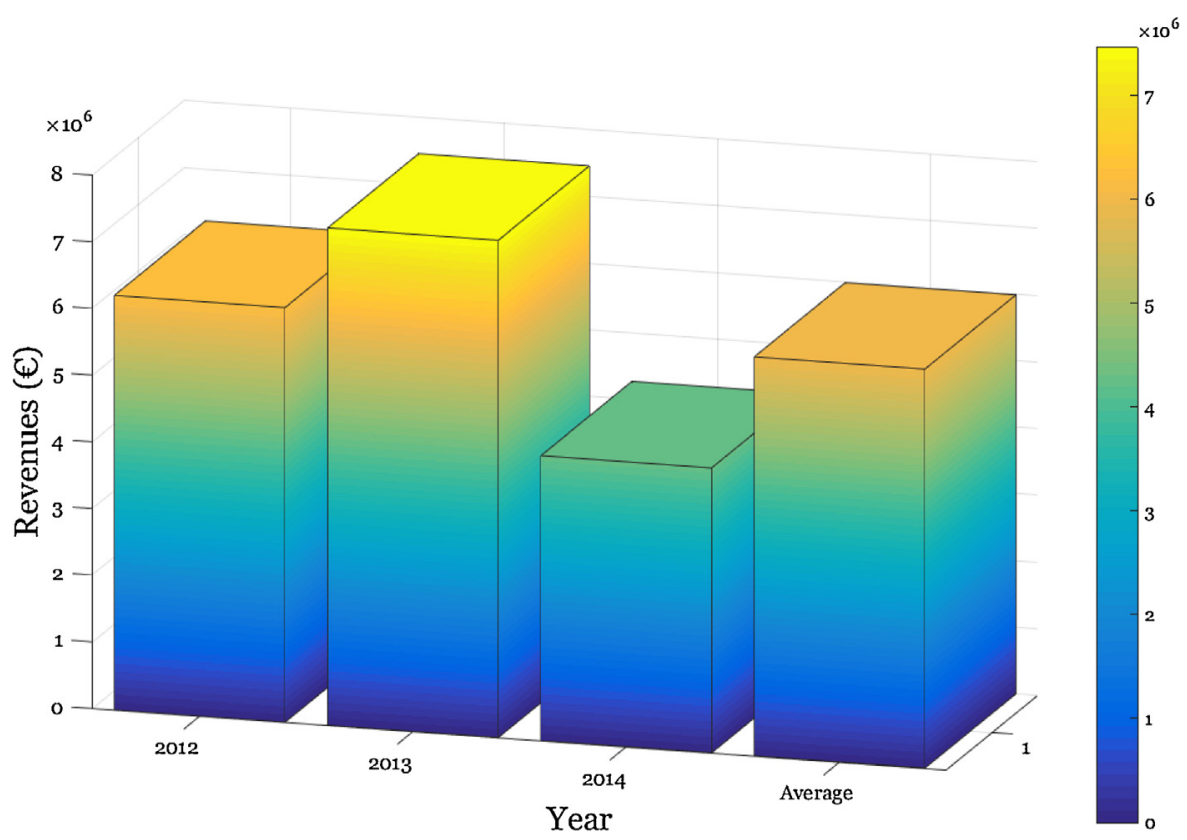

Fig. 15. Results for AACAES $50 \mathrm{MW}, 500 \mathrm{MWh}$ and $70 \%$ efficiency and FW $60 \mathrm{MW}, 15 \mathrm{MWh}$ and efficiency $90 \%$.

Operation and maintenance costs are taken from [31]. For FW the fixed $O \& M$ costs are $5.2 € / K W$-yr and the variable costs are $2.0 € \mid$ MWh. For AACAES, also the fixed O\&M costs are increased by $40 \%$ when compared to D-CAES, to $5.46 € / \mathrm{KW}$-yr. For the AACAES variable costs, as no natural gas is consumed in this case, they are considered the same as for PHES, $0.22 € / \mathrm{MWh}$.

Table 6 shows the results for the cost benefit analysis. The calculations were performed as in Case study 1. For the assessment of $\iota$ average yearly benefit over years 2012-2014, depicted in

Table 5

Cost benefit results for case study 1 .

\begin{tabular}{lll}
\hline & Average 2012-2014 & 2014 \\
\hline$\psi($ yr) & 17.30 & 26.63 \\
$\iota$ at 20 years $(\%)$ & 1 & -3 \\
$\iota$ at 15 years $(\%)$ & -2 & -6 \\
$\iota$ at 10 years $(\%)$ & -9 & -15 \\
\hline
\end{tabular}

Fig. 15, was considered. Parameter $\iota$ was calculated for $N=20,15$ and 10 years. Two payback periods were calculated with the average yearly benefits over years 2012-2014 first and with only 2014 yearly benefits second. The results demonstrate that this system will take 10 years to be paid back with the yearly benefit averaged over years 2012-2014. With yearly benefits from year 2014 , the system will be bayed back in almost 15 years. With the average yearly benefit, $\iota$ was positive with $N=10$ years, achieving $7.72 \%$ around 20 years of usage. For the yearly benefit of $2014, \iota$

Table 6

Cost benefit results for case study 2 .

\begin{tabular}{lll}
\hline & Average 2012-2014 & 2014 \\
\hline$\psi$ & 10.00 & 14.64 \\
$\iota$ at 20 years (\%) & 7.72 & 3 \\
$\iota$ at 15 years (\%) & 5.53 & 0.31 \\
$\iota$ at 10 years $(\%)$ & 0.00 & -6.39 \\
\hline
\end{tabular}




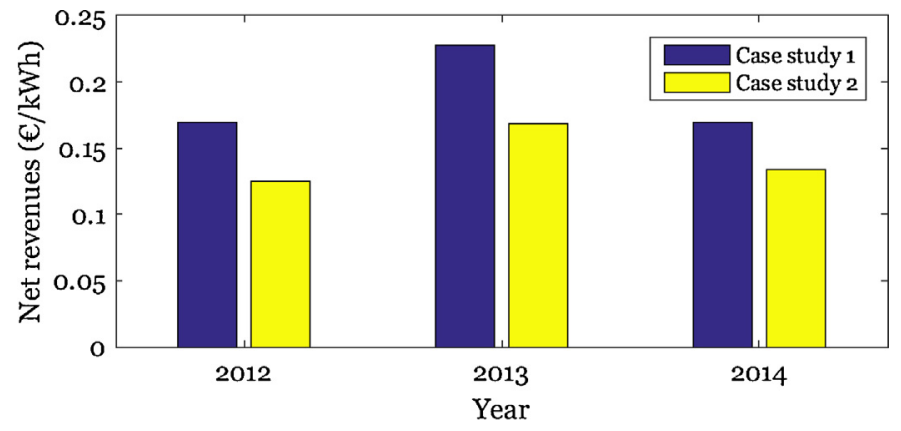

Fig. 16. Net yearly benefits for both case studies.

reaches positive values after 15 years of usage, achieving $3 \%$ after 20 years.

The net yearly benefit per kWh of energy sold for both case studies and the three years under analysis are shown in Fig. 16. The yearly benefit per KWh is higher in case study 1 . However, the amount of energy sold is higher in case study 2, as shown in Fig. 17. Therefore, the normalized yearly benefit is higher for case study 2 , as can be seen from comparing Figs. 14 and 15 .

\subsection{Discussion}

The results obtained in the last two case studies (around 10-27 years of payback time) indicate that systems similar to the ones presented in this paper have, under certain conditions, potential to be cost effective. By varying ratings for the devices used, we could increase yearly benefits by up to $256 \%$. We have shown how the costs, size and efficiency of the devices impact the feasibility of ESS.

Further integration of variable RES is expected to increase potential revenues from balancing provision. Additionally, with the increasing deployment and maturity of energy storage technologies, their investment and maintenance costs are expected to decrease, while their effective life span is expected to increase. This fact, associated with the potential higher volatility of energy prices due to variable RES integration, increases the potential for profitability of systems as the one presented in this paper. Of course, other factors, such as future energy policies, market regulation, price variations and maintenance costs, should be taken into account and optimization techniques are very useful for assessing the potential profit of the ESS. An example of a different, but complementary approach, is presented in [29] where the size of a single device energy storage system is optimized for the needs of different European markets, comparing two distinct technologies.

The results presented in the case studies, such as the payback period or the internal rate of return may explain why although the

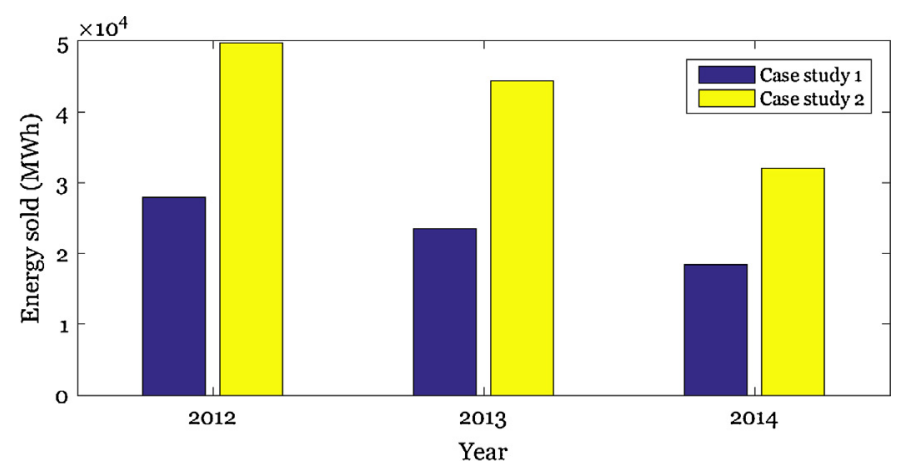

Fig. 17. Amounts of energy sold in both case studies.
ESS can be financially feasible and viable, it has not yet been deployed. The high risk associated with new technologies and business models is another likely reason. Furthermore, the power system stakeholders are seen as risk-averse, partially due to the need for presenting high levels of reliability, which strengthens the impact of high risk. Finally, there may be other reasons behind the non-deployment of these systems and technologies, which should be carefully evaluated. These seem to be of neither technological nor financial nature.

\section{Conclusions}

In this paper we presented a novel model of a dual energy storage system using two different storage technologies, trading simultaneously in two energy markets. We have adopted pattern search to find optimal strategies to operate this system. We have analysed the impact of using a dual energy storage device system and of different buying and selling strategies for weekdays and weekends. We have shown that it is possible to increase the revenues by up to $256 \%$ compared to using a single energy storage device. We have observed that, for the price data used, no significant improvement was obtained by using different buying and selling strategies for weekdays and weekends. This might change with different price data, though. We have studied impact of size, efficiencies and market price variation on the ESS yearly benefits. Finally, using two case studies we have demonstrated that, depending on the level of the costs and efficiency of the devices used to build this system, this type of systems can be already cost effective.

In the framework of an increasing amount of intermittent electricity generation, the price fluctuations in the market are expected to increase, which will then support the increase of the yearly benefits and reduce the payback period of the energy storage systems. Therefore, with the increasing need for electricity network flexibility, the potential of systems like the one presented in this paper is high. Nonetheless, that will depend on many aspects influenced by future decisions and market behaviours, which we cannot take into consideration at this stage.

In our future work, we intend to analyse the impact of imperfect price prediction on the economic benefit obtained and more advanced buying/selling strategies for ESS.

\section{Acknowledgements}

The authors gratefully acknowledge Madeleine Gibescu for the inputs and feedback provided for the research behind this paper, the Amsterdam Power eXchange (APX) who provided the energy market data that has been used in this paper, and KBB for providing the map shown on Appendix B of this paper.

\section{Appendix A. Volatility of the Dutch day-ahead and balancing market for years 2012 and 2013}

To calculate the historical price volatility towards the previous time slot $\left(\sigma_{t_{j}-t_{j-1}}^{j, \delta, j, t_{j}}\right)$ for market $j$ and day $\delta$ we used Eq. (30). Historical price volatility is the standard deviation of price return $v_{t_{j}-t_{j-1}}^{j, \delta, t_{j}}$ calculated by Eq. (31). In these equations, $p^{j, \delta, t_{j}}$ is the spot price at time $t_{j}, p^{j, \delta, t_{j-1}}$ the spot price at time $t_{j-1}, n_{T_{j}}$ is the number of time periods of the market ( $24 \mathrm{~h}$ or 96 PTUs) and $\bar{v}^{j, \delta}$ is the mean of the price quotients $v_{t_{j}-t_{j-1}}^{j, \delta t_{j}}$ in market $j$ at day $\delta$. We have applied Eq. (30) to the Dutch day-ahead market prices and to both upward and downward prices of the balancing market. For the balancing market, PTU is used instead of the hour which is used in the 

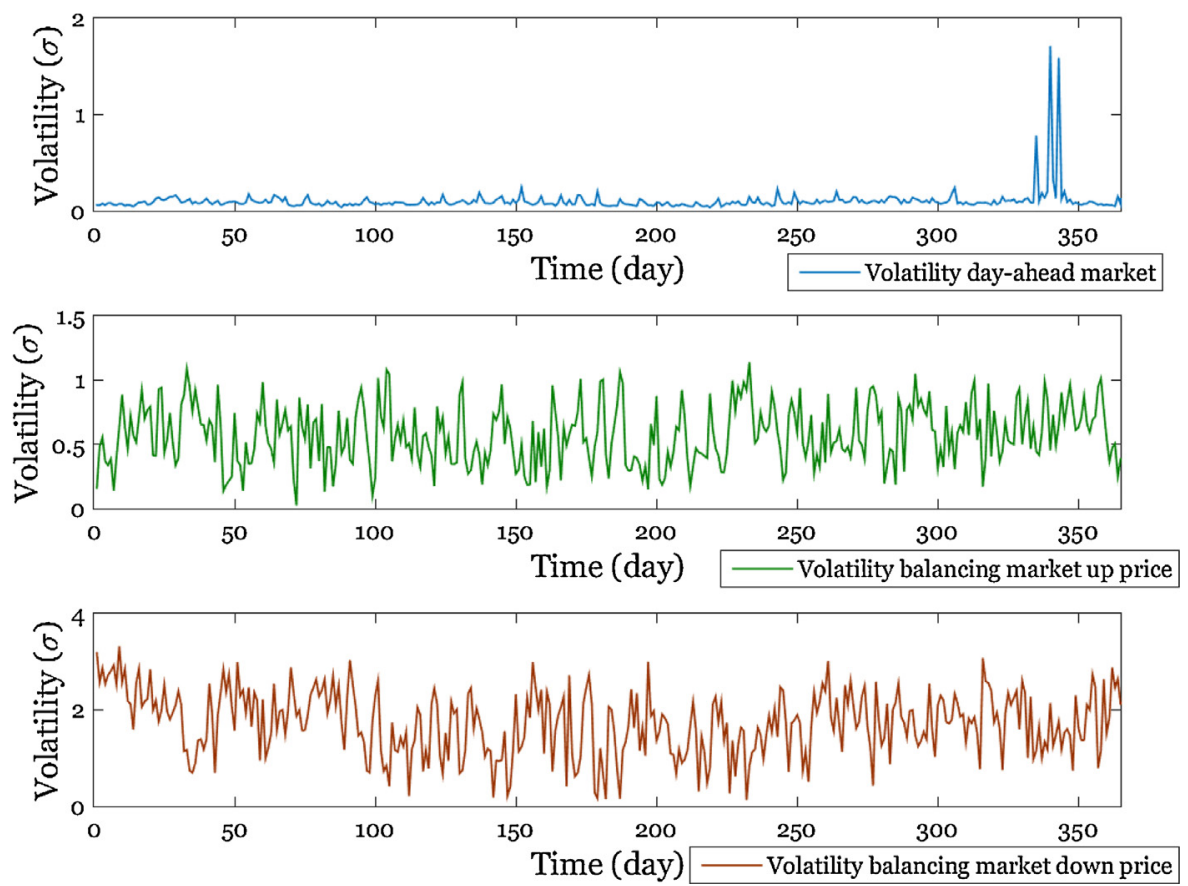

Fig. 18. Market volatility towards previous time slot (hour or PTU, depending on the market) for the 2012 day-ahead and balancing market prices.
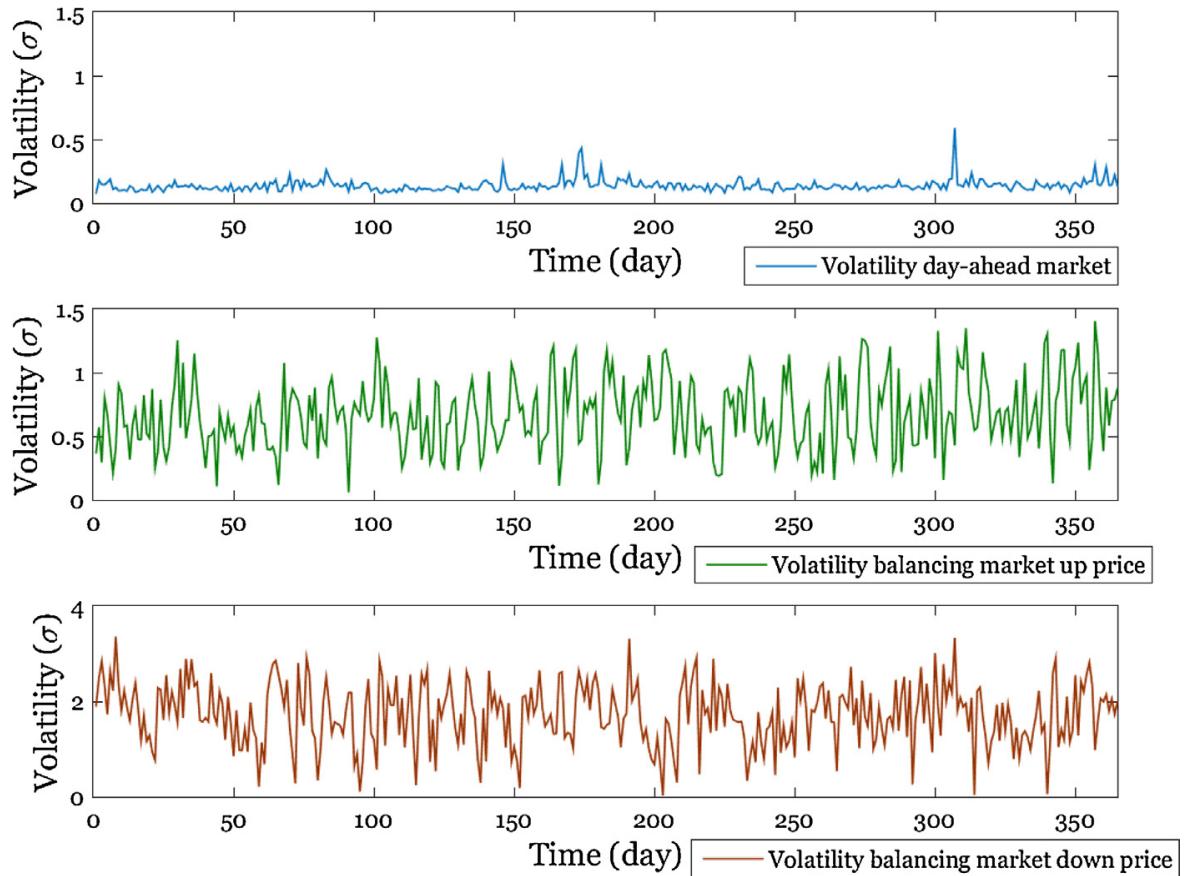

Fig. 19. Market volatility towards previous time slot (hour or PTU, depending on the market) for the 2013 day-ahead and balancing market prices.

day-ahead market.

$\sigma_{t_{j}-t_{j-1}}^{j, \delta}=\sqrt{\sum_{t_{j} \in T_{j}} \frac{\left(v_{t_{j}-t_{j-1}}^{j, \delta, t_{j}}-\bar{v}^{j, \delta}\right)^{2}}{n_{T_{j}}-1}}$

$v_{t_{j}-t_{j-1}^{j, \delta}}^{j, t_{j}, \delta, t_{j}}=\frac{p^{j, \delta, t_{j}}}{p^{j, \delta, t_{j-1}}}$
In Figs. 18 and 19 are presented the volatility towards the previous time slot (hour or ptu) of the Dutch day-ahead and balancing market for the years 2012 and 2013, respectively.

\section{Appendix B. Possible technologies that can be used for energy storage}

We have analysed the possible technologies that can be used as bulk and high power technologies, respectively. 


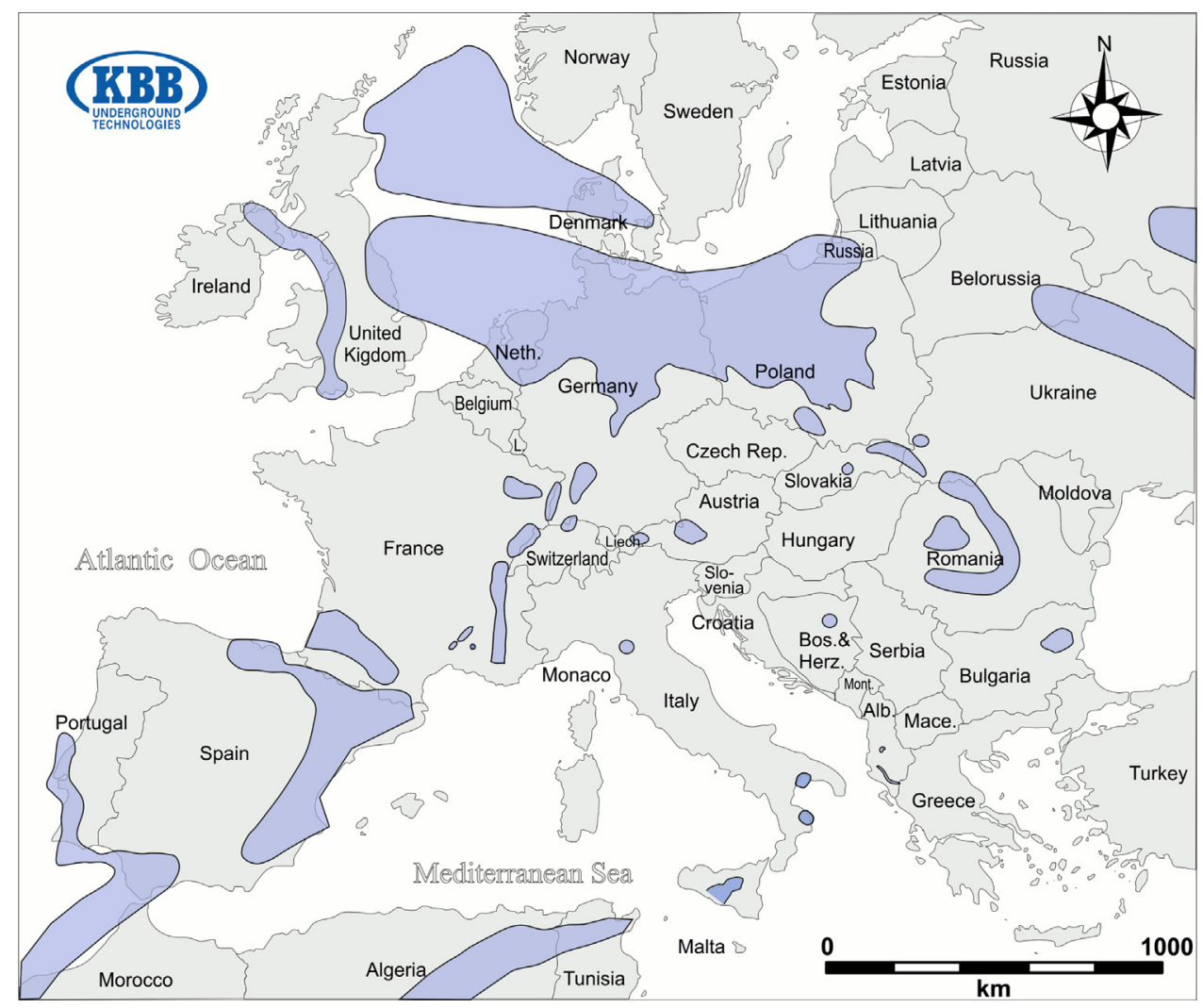

Fig. 20. Location of underground salt reservoirs in Europe. Courtesy of KBB technologies.

For bulk technologies, the available options are: pumped-hydro energy storage (PHES), diabatic compressed air energy storage (DCAES) and adiabatic advanced compressed air energy storage (AACAES). The PHES is widely used and is the most mature bulk technology. However, this technology is dependent on geological conditions and availability of possible sites. The geological conditions in The Netherlandsare not optimal to build traditional PHES systems, especially due to the flat landscape. The CAES technologies are appropriate bulk technologies for The Netherlands, as these technologies can be built using either the existing underground salt deposits in the centre and north of the country or the depleted gas reservoirs in the north of the country. Fig. 20 shows the location of underground salt reservoirs in Europe. A substantial area of The Netherlands lies above a region where these salt reservoirs are located. These reservoirs can be used to build underground caves which in turn will be part of a compressed air energy storage system (CAES).

The first D-CAES system was installed in 1978 in Germany [11]. This technology uses natural gas to both charge and discharge the underground reservoirs. Although AACAES is currently a theoretical technology, the test results are very promising. Instead of gasbased compressors, it can use electric compressors. Furthermore, the resulting heat of the air compression which occurs when the device charges is stored and used to heat the expanding air when the device discharges. These AACAES developments increase the efficiency of this technology and reduce operation costs when compared with D-CAES [18]. All bulk technologies have a very long durability of 20-100 years. This includes CAES; the first equipment installed is still functional after 37 years [11].

For the high power energy storage several technologies can be considered [11]. Among those, one may highlight lead-acid, lithium-ion, nickel-cadmium, sodium-sulphur, zebra $\left(\mathrm{NaNiCl}_{2}\right)$ batteries, and flywheels. An appropriate technology should lead to a very fast response time (in order of few seconds) to any mode switch between charging, idle and discharging. Moreover, such technology should have a modular capacity allowing a realistic implementation of the power and energy size specifications of the device. In the long term, another important aspect is the cycling durability, as the high power device will be working very frequently. Lead-acid batteries are a mature technology with low initial costs. Lithium-ion batteries present good durability and efficiency. Nickel-cadmium batteries present good durability and robustness to deep discharges. Sodium-sulphur batteries present the advantages of low maintenance and below average initial costs. Zebra $\left(\mathrm{NaNiCl}_{2}\right)$ batteries present good robustness to self discharge. Flywheels have the advantage of a theoretical unlimited amount of charge and discharge cycles.

\section{References}

[1] European Commission, “COM (2013) 169 final - Green Paper - A 2030 framework for climate and energy policies", Brussels, Belgium, (2013) .

[2] European Commission, "COM (2011) 112 final - A roadmap for moving to a competitive low carbon economy in 2050", Brussels, Belgium, (2011).

[3] Z. Ming, Z. Kun, L. Daoxin, Overall review of pumped-hydro energy storage in China: status quo, operation mechanism and policy barriers, Renew. Sustain. Energy Rev. 17 (2013, January) 35-43.

[4] M. Esteban, J. Portugal-Pereira, Post-disaster resilience of a 100\% renewable energy system in Japan, Energy 68 (2014, April) 756-764.

[5] I.G. Mason, S.C. Page, A.G. Williamson, Security of supply, energy spillage control and peaking options within a 100\% renewable electricity system for New Zealand, Energy Policy 60 (2013, September) 324-333.

[6] J. Eyer, G. Corey, "Energy Storage for the Electricity Grid: Benefits and Market Potential Assessment Guide", Sandia report 2010-0815, Sandia National Laboratories, Livermore and Albuquerque, USA, 2010.

[7] EPRI, "Electricity Energy Storage Technology Options - A White Paper Primer on Applications, Costs and Benefits", report, EPRI, Palo Alto, USA, 2010.

[8] B. Dursun, B. Alboyaci, The contribution of wind-hydro pumped storage systems in meeting Turkey's electric energy demand, Renew. Sustain. Energy Rev. 14 (7) (2010, September) 1979-1988.

[9] G. Papaefthymiou, K. Grave, K. Dragoon, "Flexibility options in electricity systems”, Ecofys report, European Copper Institute, Berlin, Germany, 2014. 
[10] Grid Tech European Project webpage, http://www.gridtech.eu/, (accessed 12.07.15).

[11] H.L. Ferreira, R. Garde, G. Fulli, W. Kling, J.P. Lopes, Characterisation of electrical energy storage technologies, Energy 53 (2013, May) 288-298.

[12] F. Borggrefe, K. Neuhoff, "Balancing and intraday market design: options for wind integration", Smart Power Market Project report, Climate Policy Initiative, DIW Berlin, Berlin, Germany, 2011.

[13] D. Connolly, H. Lund, P. Finn, B.V. Mathiesen, M. Leahy, Practical operation strategies for pumped hydroelectric energy storage (PHES) utilising electricity price arbitrage, Energy Policy 39 (7) (2011, May) 4189-4196.

[14] G.N. Bathurst, G. Strbac, Value of combining energy storage and wind in shortterm energy and balancing markets, Electr. Power Syst. Res. 67 (1) (2003, October) $1-8$.

[15] A. Zucker, T. Hinchliffe, A. Spisto, Assessing Storage Value in Electricity Markets - A literature review", JRC scientific and policy reports, Petten, The Netherlands, (2013).

[16] R. Hemmati, H. Saboori, Emergence of hybrid energy storage systems in renewable energy and transport applications - a review, Renew. Sustain. Energy Rev. 65 (2016, November) 11-23.

[17] H. Lopes Ferreira, M. Gibescu, K. Stañková, W.L. Kling, J. Peças, Lopes, Dual technology energy storage system applied to two complementary energy markets, 12th International Conference on the European Energy Market, 19-22 May 2015, Lisbon, Portugal, 2015, pp. 1-5.

[18] C. Bullough, C. Gatzen, C. Jakiel, M. Koller, A. Nowi, S. Zunft, Advanced adiabatic compressed air energy storage for the integration of wind energy, European Wind Energy Conference 2004, 22-25 November, London, UK, 2004.
[19] Commodities-now.com webpage, http://www.commodities-now.com/reports/general/9619-apx-endex-2011-review.html, (accessed 08.02.15).

[20] J. Frunt, Analysis of balancing requirements in future sustainable and reliable power systems (PhD dissertation), Technische Universiteit Eindhoven, Eindhoven, 2011.

[21] I. Lampropoulos, J. Frunt, S. Pagliuca, W.W. De Boer, W.L. Kling, Evaluation and assessment on balancing resource, Proc. 2011 8th Int. Conf. the European Energy Market (2011).

[22] I. Simonsen, Volatility of power markets, Phys. A: Stat. Mech. Appl. 355 (1) (2005, September) 10-20.

[23] C.K. Ekman, S.H. Jensen, Prospects for large scale electricity storage in Denmark, Energy Convers. Manag. 51 (6) (2010, June) 1140-1147.

[25] R. Hooke, T.A. Jeeves, "Direct search" solution of numerical and statistical problems, J. Assoc. Comput. Mach. (ACM) 8 (2) (1961, April) 212-229.

[26] W.C. Davidon, Variable metric method for minimization, SIAM J. Optim. 1 (1) (1991) $1-17$.

[27] European Central Bank webpage, https://www.ecb.europa.eu/stats/exchange/eurofxref/html/index.en.html, (accessed 15.07.15).

[28] TenneT data export website, http://energieinfo.tennet.org/-dataexport/ exporteerdatacountry.asp, (last accessed 16.05.16).

[29] D. Zafirakis, K.J. Chalvatzis, G. Baiocchi, G. Daskalakis, The value of arbitrage for energy storage: Evidence from European electricity markets, Appl. Energy 184 (c) (2017) $971-986$.

[30] http://www.accountingtools.com/payback-period-formula, (last accessed 14.09.16)

[31] B. Zakeri, S. Syri, Electrical energy storage systems: a comparative life cycle cost analysis, Renew. Sustain. Energy Rev. 42 (2015, February) 569-596. 